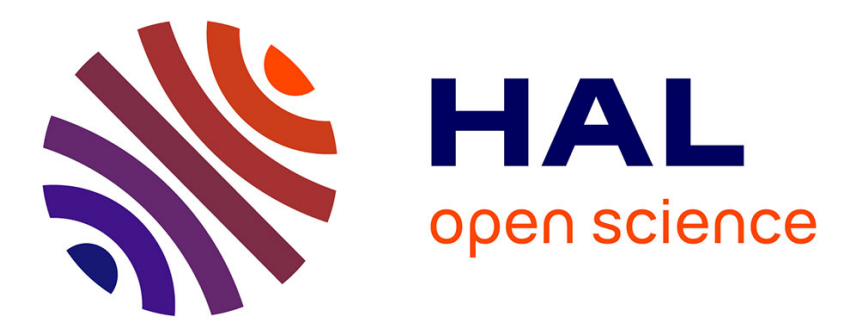

\title{
Using the dynamic Phase Inversion Temperature (PIT) as a fast and effective method to track optimum formulation for Enhanced Oil Recovery
}

Guillaume Lemahieu, Jesus F. Ontiveros, Valérie Molinier, Jean-Marie Aubry

\section{- To cite this version:}

Guillaume Lemahieu, Jesus F. Ontiveros, Valérie Molinier, Jean-Marie Aubry. Using the dynamic Phase Inversion Temperature (PIT) as a fast and effective method to track optimum formulation for Enhanced Oil Recovery. Journal of Colloid and Interface Science, 2019, 557, pp.746 - 756. 10.1016/j.jcis.2019.09.050 . hal-03487320

\section{HAL Id: hal-03487320 \\ https://hal.science/hal-03487320}

Submitted on 21 Dec 2021

HAL is a multi-disciplinary open access archive for the deposit and dissemination of scientific research documents, whether they are published or not. The documents may come from teaching and research institutions in France or abroad, or from public or private research centers.
L'archive ouverte pluridisciplinaire HAL, est destinée au dépôt et à la diffusion de documents scientifiques de niveau recherche, publiés ou non, émanant des établissements d'enseignement et de recherche français ou étrangers, des laboratoires publics ou privés.

\section{(ㅇ)(1) $\$$}

Distributed under a Creative Commons Attribution - NonCommerciall 4.0 International 


\section{Using the dynamic Phase Inversion Temperature (PIT) as a fast and effective method to track optimum formulation for Enhanced Oil Recovery}

Guillaume Lemahieu ${ }^{1}$, Jesus F. Ontiveros ${ }^{1}$, Valérie Molinier ${ }^{2}$, Jean-Marie Aubry ${ }^{1 *}$

(1) Univ. Lille, CNRS, Centrale Lille, ENSCL, Univ. Artois, UMR 8181- UCCS - Unité de Catalyse et Chimie du Solide, F-59000 Lille, France.

(2) Total Exploration Production, Pôle d'Etudes et de Recherche de Lacq, B.P. 47, 64170 Lacq, France.

jean-marie.aubry@univ-lille.fr 


\begin{abstract}

\section{Hypothesis}

The attainment of ultralow interfacial tensions between crude oil and injected aqueous surfactant mixtures is a prerequisite for an effective chemical Enhanced Oil Recovery (EOR). The dynamic Phase Inversion Temperature (PIT) of SOW emulsified systems is very close to the "optimal temperature" currently identified with equilibrated SOW systems. Therefore, the PIT could be a tool to track the "optimum formulation" and determine EACN of crude oils. Additionally, the PIT-slope method could be used to characterize EOR surfactants.
\end{abstract}

\title{
Experiments
}

The PIT of $3 \% \mathrm{C}_{10} \mathrm{E}_{4} /$ crude oils/water emulsions are compared to the PIT for $n$-alkanes in order to estimate crude oils EACN. The "PIT-slope" method is applied to different non-ionic and ionic extended EOR surfactants to assess their amphiphilicity. The conductivity profiles of different EOR surfactants/crude oil/ $\mathrm{NaCl}_{(\mathrm{aq})}$ emulsions at $\mathrm{f}_{\mathrm{w}}=0.5$ are determined at different salinities.

\section{Findings}

Considering the PIT shifts and shapes, it is possible to infer relevant information on the crude oil such as precise EACN and relationships between optimum salinity and temperature. The "PIT-Slope method" allows ranking EOR surfactants according to their amphiphilicity. Mixing both results allows a faster determination of key parameters used in EOR compared to studies with equilibrated system.

Keywords: Phase Inversion Temperature, Winsor III microemulsion, Crude oil, Fast screening, Salinity. 


\section{Introduction}

It is commonly agreed that only one third of the crude oil trapped inside the reservoirs is extracted after primary and secondary recoveries. Among the Enhanced Oil Recovery (EOR) techniques, surfactant polymer (SP) and alkali surfactant polymer (ASP) flooding have proved their effectiveness in decreasing residual oil saturation. The addition of appropriate surfactants to polymer flooding drastically reduces the interfacial tension between crude oil and water, which allows oil mobilization and flow. The choice of the surfactant system is essential to decrease the interfacial tension enough to get an effective recovery [1-3]. In particular, the affinity of the surfactants for crude oil is crucial. To select the best surfactant systems for a given crude oil, some parameters related to the crude oil nature such as the Equivalent Alkane Carbon Number (EACN) have been introduced. To adjust the affinity of the surfactants to the crude oil, the salinity of the water flooding can be turned to maximize high solubilization of brine and oil [4]. The most effective approach consists in the obtainment of ultra-low interfacial tension occurring within the Winsor III three-phase microemulsion systems (WIII) [5].

In practice, the best surfactant system is determined by salinity scans at the reservoir temperature and the optimum formulation (corresponding to the minimum of interfacial tension) is visually determined at the salinity for which a WIII system is obtained, with the middle phase volume well-balanced between water and oil. Salinity scans are visualized at equilibrium, which requires in some cases lengthy equilibrium times to unambiguously identify the phase behavior of crude oil-based systems. In the case of well-defined oils, the equilibrium time is usually short (from several minutes to hours), but it can be much longer with some crude oils (several weeks until several months), which is a restricting factor to a fast determination of the appropriate surfactant system. Also, not all surfactant systems lead to threephase microemulsion systems but rather form gels or viscous phases over the salinity gradient, which is highly undesirable.

The study presented here shows that a fast determination of the optimum formulation in petroleum system can be achieved by dynamic phase inversion temperature (PIT) of emulsions. By analyzing the PIT curve obtained, it is possible to predict the formation of WIII systems or not at equilibrium, and also to carry out rapid screening of pre-selected EOR surfactant formulations before carrying out salinity scans at equilibrium. The dynamic phase inversion allows also classifying EOR surfactants to guide formulators in their search for the most appropriate surfactant system.

\subsection{Crude oil microemulsions related to Chemical EOR}

Chemical EOR techniques are based on the injection of low interfacial tension fluids in order to reduce the capillary forces which trap crude oil inside the reservoir pores. The oil/water interfacial tension must be depressed to ultralow values $\left(10^{-3} \mathrm{mN} / \mathrm{m}\right.$ and lower) to significantly enhance the microscopic displacement efficiency, as shown by relation (1) [6].

$$
\Delta P=2 \gamma\left(\frac{1}{r_{2}}-\frac{1}{r_{1}}\right)
$$

where $\Delta \mathrm{P}, \gamma, \mathrm{r}_{1}$ and $\mathrm{r}_{2}$ are the pressure difference, the interfacial tension and the curvature radii respectively.

The ultralow interfacial tension value is obtained by addition of surfactant molecules to the water flooding [7]. These surfactants modify the phase behavior of crude oil/water system, and under specific conditions, can lead to the formation of three-phase microemulsion systems (Winsor III) in which the oil/water interfacial tension reaches the required ultralow values [8-10]. Such systems can be obtained by balancing the surfactant affinity for the aqueous and oil phases to suit the crude oil under study. The modification of the surfactant affinity can be made by tuning the temperature and the salinity, among other variables. 
In the EOR field, temperature is a fixed parameter because it equals the reservoir temperature. In order to reach the optimized WIII microemulsion system, the salinity of the aqueous phase remains the variable parameter to adjust the surfactant affinity. In that way, the minimum of interfacial tension, called optimum formulation, is determined by mono-dimensional salinity scans carried out at equilibrium and at the reservoir temperature. This optimum formulation is determined at the salinity for which the WIII microemulsion incorporates equal amounts of water and oil.

From this equilibrated salinity scan, it is possible to determine the optimum salinity $\mathrm{S}^{*}$ but also the efficiency of the surfactant system, which is evidenced by the microemulsion volume related to the volume of surfactant used. To express this efficiency, the solubilization ratio $\sigma^{*}$, expressed in $\mathrm{cm}^{3} / \mathrm{cm}^{3}$ or $\mathrm{cc} / \mathrm{cc}$, is often used [5,11].

$$
\sigma^{*}=\frac{V_{O \text { or } W / \mu}}{V_{S}}=\frac{\text { Volume of } \text { water or oil in the microemulsion at optimum }}{\text { Volume of surfactant in the system }}
$$

From the solubilization ratio, it is also possible to infer the minimum interfacial tension at the optimum formulation by considering the model proposed by Huh [12]. In this model, the middle-phase microemulsion is described as alternating layers of oil and water separated by a surfactant film. This description is basically in line with the bicontinuous structure of WIII microemulsions and the zero curvature of the surfactant film at optimum. From this simplified description, Huh derived the equations that rule the equilibrium, governed by van der Waal's attraction, electrostatic repulsion and entropy decrease. In that way, the thickness of the layers, directly related to the solubilization ratio at optimum $\sigma^{*}$, can be calculated. The minimum interfacial tension is derived by calculating the energy required to divide in two a volume of microemulsion phase, thus creating two new microemulsion/excess phase interfaces. The Huh equation is displayed below [12]:

$$
\frac{\sigma^{* 2} \cdot \gamma^{*}}{\cos \left(\frac{\pi . \Phi}{2}\right)}=\frac{A}{96 \pi \tau^{2}} \quad \text { with } \quad A=A_{i i}+A_{j j}-2 A_{i j}
$$

where $\sigma^{*}$ is the solubilization ratio, $\gamma^{*}$ is the minimum of interfacial tension, $\Phi$ the volume fraction of oil or water, $A_{i j}$ the Hamaker constant between phases $\mathrm{i}$ (oil) and $\mathrm{j}$ (water), and $\tau$ the apparent thickness of the surfactant layer at the interface, which is close to the length of the surfactant molecule.

To simplify this equation, the parameter $a_{H}$ has been introduced and depends on the surfactant type [7]. With an equal volume fraction of oil and water $(\Phi=0.5)$, the classical Huh equation is obtained as displayed below:

$$
\gamma^{*}=a_{H} \frac{\cos \left(\frac{\pi}{4}\right)}{\sigma^{* 2}} \text { with } a_{H}=\frac{A}{96 \pi \tau^{2}}
$$

The parameter $\mathrm{a}_{\mathrm{H}}$ has been already characterized in the literature for a wide range of trade surfactants (Table 2). According to the Huh equation, a minimal solubilization ratio of $15 \mathrm{cc} / \mathrm{cc}$ is needed to reach the interfacial tension value of $10^{-3} \mathrm{mN} / \mathrm{m}$ required for EOR applications. 
Table 1: $a_{H}$ values for three types of standard EOR surfactants

\begin{tabular}{cccc}
\hline Surfactant type & Chemical structures & $\mathbf{a}_{\mathbf{H}}(\mathbf{m N} / \mathbf{m})$ & References \\
\hline Sulfonated alkyl benzenes & $0.48 \pm 0.05$ & Verkruyse and Salter [13] \\
$\begin{array}{c}\text { Sulfonated alkanes and } \alpha- \\
\text { olefins }\end{array}$ & Graciaa et al. [14] & Barakat et al. [15] \\
\hline
\end{tabular}

By approximating $\mathrm{a}_{\mathrm{H}}$ to a mean value of $\sim 0.42$ for all surfactants, the Huh equation can be simplified as follows:

$$
\gamma^{*}=\frac{0.3}{\sigma^{* 2}}
$$

This simplified expression is often used in practice. The interfacial tension has been shown later to correlate well with $\mathrm{kT} / \mathrm{d}^{2}$, with $\mathrm{d}$ the characteristic length in the microemulsion [16]. In the same way, a parameter based on the Huh equation named "Perfind" has been introduced by Salager $e t$ al. to evaluate the influence of formulation variables on the solubilization efficiency [17].

Another way to predict the interfacial tension is to use the Net Average Curvature (NAC) model introduced by Acosta et al [18] (Equations 6 and 7), which has been coupled with the HLD equation proposed by Salager et al [19] (Equations 8 and 9).

$$
\begin{gathered}
H_{n}=\left|\frac{1}{R_{O}}\right|-\left|\frac{1}{R_{W}}\right|=-\frac{H L D}{L} \\
H_{a}=\frac{1}{2}\left(\left|\frac{1}{R_{O}}\right|+\left|\frac{1}{R_{W}}\right|\right) \geq \frac{1}{\xi} \quad \text { with } \xi=\frac{6 . \varphi_{O} \varphi_{W} V_{M}}{A_{S}}
\end{gathered}
$$

where $\mathrm{H}_{n}$ and $\mathrm{H}_{\mathrm{a}}$ are the Net and Average curvatures respectively, $\mathrm{R}_{\mathrm{O}}$ and $\mathrm{R}_{\mathrm{W}}$ are the radii of coexisting hypothetical spherical of oil and water, $\mathrm{L}$ is a length scaling parameter proportional to the tail length of the surfactant, $\xi$ is the "characteristic length" of the microemulsion defined by De Gennes and Taupin [20], $\varphi_{O}$ and $\varphi_{\mathrm{w}}$ are the volume fraction of oil and water respectively, $V_{M}$ the volume of the middlephase microemulsion, and $A_{S}$ the surfactant interfacial area.

$$
H L D=\sigma+\ln (S)-k . E A C N+t . \Delta T+f(A)
$$

with $\sigma, \mathrm{k}$, and $\mathrm{t}$ the parameters depending on the surfactant, $\mathrm{S}$ the salinity of the aqueous phase (wt \%), EACN the equivalent alkane carbon number of the considered oil, $\Delta \mathrm{T}$ the temperature difference $\left({ }^{\circ} \mathrm{C}\right)$, A the alcohol concentration (wt\%) and a the constant depending on the alcohol type. Another way to express the HLD equation is to introduce the concept of characteristic curvature $(\mathrm{Cc})$ which redefined the original $\sigma$ parameter as mentioned below. The value of $\mathrm{Cc}$ reflects the tendency of the surfactant to form micelles (negative values of $\mathrm{Cc}$ ) or reverse micelles (positive values of $\mathrm{Cc}$ ) in the presence of a reference oil [21].

$$
H L D=C c+\ln (S)-k \cdot E A C N+t . \Delta T+f(A)
$$

The HLD equation allows a prediction of the optimum salinity as a function of the different parameters of the Surfactant/Oil/Water system used, such as the EACN, the temperature and the surfactant nature, but it does not allow to predict the amount of oil and water dissolved in the microemulsion phase. 
The NAC model assumes that any microemulsion can be represented by coexisting hypothetical spherical droplets of oil and water, with the reciprocal of oil and water droplets as the curvature of microemulsion (Equations 6 and 7). Characterizing this curvature allows predicting the global phase composition as well as evaluating phase behavior, solubilization ability and IFT at optimum induced by surfactants [22-25].

\subsection{Phase Inversion Temperature (PIT)}

The phase inversion is defined as the transition of an oil-in-water $(\mathrm{O} / \mathrm{W})$ to a water-in-oil $(\mathrm{W} / \mathrm{O})$ emulsion (and vice versa) resulting from the change of the surfactant affinity from water to oil (and vice versa). This affinity change is induced by the variation of a formulation parameter, which is most of the time the temperature. Temperature has different influences on the phase behavior of surfactants depending whether they are ionic or non-ionic. For ionic surfactants, increasing temperature allows increasing the hydrophilicity of the surfactant by a more efficient ion pair's dissociation with thermal energy. This is the reverse effect for ethoxylated and propoxylated non-ionic surfactants: increasing temperature leads to the cleavage of hydrogen bonds between water and the surfactant, which makes the surfactant less hydrophilic. The PIT is defined as the temperature at which a surfactant/oil/water system (SOW) reverses from an oil-in-water $(\mathrm{O} / \mathrm{W})$ to a water-in-oil emulsion $(\mathrm{W} / \mathrm{O})$ and vice versa [26]. The PIT is unique for a non-ionic surfactant in a SOW system and it was found that these surfactants exhibit at the PIT the highest solubilization of oil and water, which is characteristic of the optimum formulation [27]. In other words, the SOW system exhibits a Winsor III system at the PIT if the interfacial tension is sufficiently decreased. Under stirring, such a system gives a very unstable emulsion which quickly separates into three phases as soon as the agitation is stopped. The PIT value is also a descriptor of the surfactant taken in its environment, since it results from the crossed influences of the oil and the aqueous phases [10]. Actually, the more hydrophilic the interfacial film is, the higher the PIT is.

\subsection{PIT evaluation methods}

The PIT is readily detectable by conductivity measurements. For non-ionic surfactants, at low temperature, the stirred SOW system forms an $\mathrm{O} / \mathrm{W}$ emulsion. Increasing the temperature leads to a decrease of the droplet size due to a decrease of the O/W interfacial tension. At the PIT, the SOW system reverses itself by giving a complex mixture of microemulsion with oil and water, which is less conductive than the previous $\mathrm{O} / \mathrm{W}$ emulsion. It induces a fall in conductivity at this temperature. After the PIT, the SOW system shows a conductivity close to zero because a W/O emulsion is obtained. The PIT is then defined as the temperature at which the fall in conductivity occurs (Figure 5). The experiment may be conducted on pre-equilibrated samples at various temperatures, but it can also be performed in a dynamic way by applying a constant rate of temperature increase or decrease to a continuously stirred SOW system. This last method shows an important gain in time compared to the equilibrium temperature scan, a pretty good signal visualization and a margin of error close to zero with the equilibrium procedure [28].

The PIT can also be detected by viscosity measurements because the optimum formulation reached at the PIT exhibits a minimum of viscosity $[29,30]$. This minimum is linked to the ultralow interfacial tension that allows elongating the droplets along the stream lines with almost no expense of energy [31]. On both sides of the "optimum formulation", close to the three phase area, the emulsion presents a minimum droplet size that produces 2 local maximum values of viscosity [32]. After the PIT, the W/O emulsion obtained shows a viscosity decrease with temperature due to the growth of droplet sizes up to a limit viscosity value (Figure 1). A drawback of the viscosity monitoring method is that the data can be only recorded during an increasing ramp of temperature because of the rapid phase separation of the W/O emulsion at high temperature inside the cone-plate rheometer. During conductivity measurements, the sample is continuously stirred and it is possible to record data in back and forth modes around the inversion, which provides a better precision for PIT determination. 

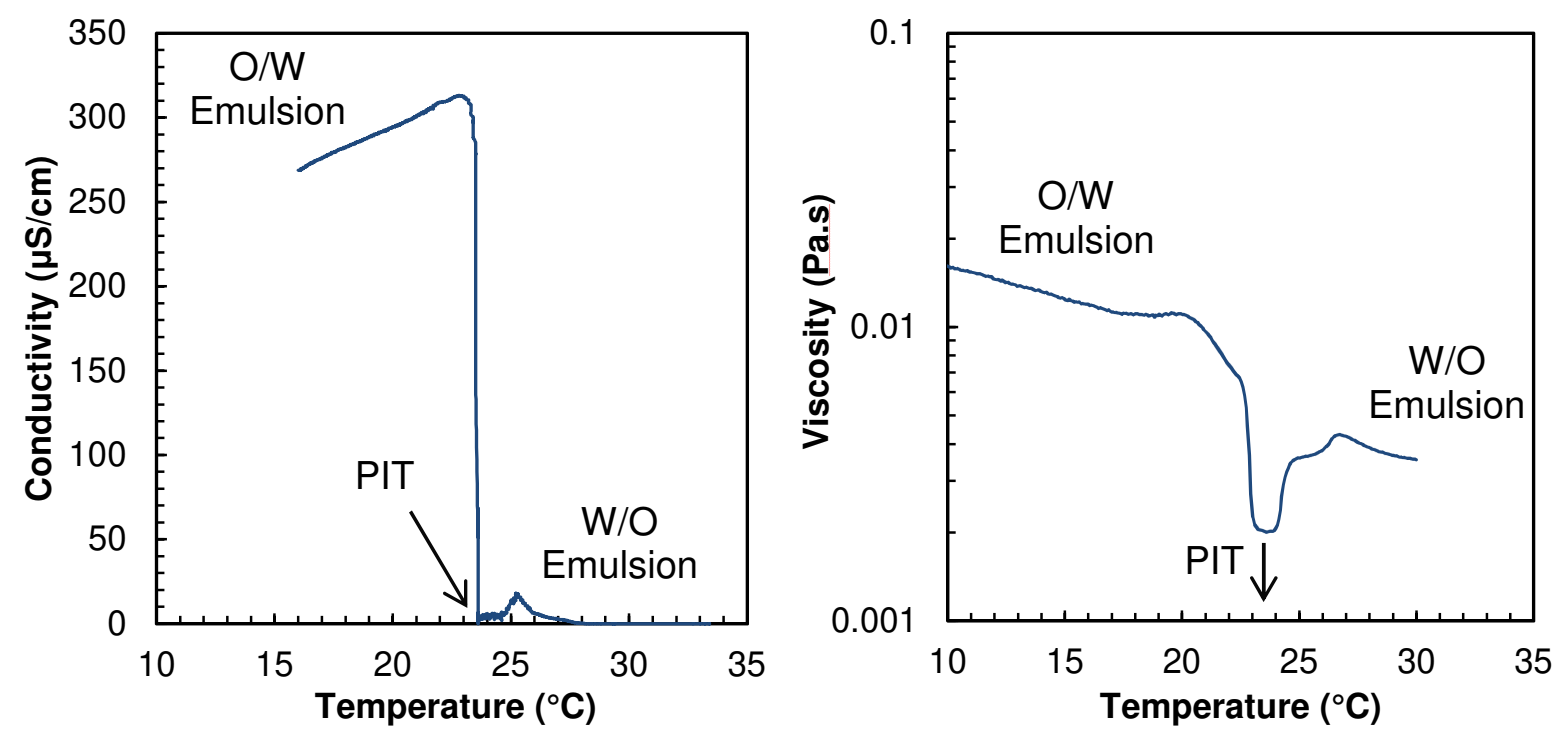

Figure 1: Dynamic phase inversion of $C_{10} E_{4} / n$-Octane/10 $0^{-2} M \mathrm{NaCl}_{(a q)}$ monitored by conductivity (left) or viscosity (Right)

\section{Materials and methods}

The following study was performed using four crude oils (A, B, C, D) and one gas condensate (E) provided by TOTAL SA. The different characteristics of these petroleum oils such as Total Acid Number (TAN), Total Base Number (TBN), ASCI index, viscosity and density at $25^{\circ} \mathrm{C}$, API degree and SARA fraction are listed below (Table 1). TAN and TBN of crude oils were determined using respectively the standard method ASTM D664 [33] and ASTM D2896 [34], and ASCI index was carried out according to a specific method developed by TOTAL [35]. API degree was calculated from density extrapolated at $15^{\circ} \mathrm{C}$ and SARA fractions were determined by TLC-FID.

The EOR surfactants used in this study were developed and provided by BASF. These surfactants have various structure types among carboxymethylated and sulfated alkoxy alcohols for ionic surfactants and ethoxylated alcohols $\left(\mathrm{C}_{\mathrm{i}} \mathrm{EO}_{\mathrm{j}}\right)$ for non-ionic surfactants. Hydrophobic tails may be linear or branched chains having between 10 and 18 carbons. Tween 85 used was purchased from Sigma. The $\mathrm{C}_{10} \mathrm{E}_{4}$ surfactant used for the characterization of EOR surfactants was synthesized in the lab and distilled to obtain an ultra-pure sample (> 99\%) [36]. $n$-Octane (> 98\%) was purchased from Sigma Aldrich. The reference system used for the PIT-Slope method was prepared by addition of $3 \mathrm{wt} \%$ pure $\mathrm{C}_{10} \mathrm{E}_{4}$ to a mixture of $10^{-2} \mathrm{M} \mathrm{NaCl}_{\mathrm{aq}} / n$-Octane at a mass fraction of water equal to 0.5 . The other $n$-alkanes used for crude oil EACN calibration or for comparative studies to petroleum oils were purchased from different suppliers (Sigma Aldrich, Alfa Aesar) with a high degree of purity (>99\%).

All dynamic PIT experiments (viscosity and conductivity) were performed with an increasing and decreasing temperature rate of $1^{\circ} \mathrm{C} / \mathrm{min}$. For conductivity experiments, data were recorded using a CDM210 conductivity meter from MeterLab® with a coupled conductivity-temperature electrode CDC641T from Radiometer Analytical® after one increasing and decreasing temperature cycle to homogenise the sample. The results were processed thanks to Labview software. In these experiments, the stirring rate of the sample was fixed at $700 \mathrm{rpm}$. For PIT determination in petroleum systems, the same system was employed and each sample was prepared in order to have a water/oil volume ratio (WOR) equal to 1. Each sample had a volume between 10 and $20 \mathrm{~mL}$ to get representative measurements. For viscosity measurements, $2 \mathrm{~mL}$ sample was placed in the cap of a cone-plate gap (6 $\mathrm{cm}, 2^{\circ}$ ) of a Kinexus rheometer from Malvern at a constant shear rate of $500 \mathrm{~s}^{-1}$, as detailed elsewhere [29]. 
Table 2: Specific data of crude oils used

\begin{tabular}{cccccc}
\hline Crude oil & A & B & C & D & E \\
\hline TAN (mg KOH/g) & 2.0 & 0.5 & 0.3 & 0.1 & 0.3 \\
TBN (mg eq KOH/g) & 2.5 & 1.7 & 0.7 & 0.6 & 0.3 \\
ASCI index & 17 & 17 & 13 & 19 & $\mathrm{n} / \mathrm{a}$ \\
Viscosity at $25^{\circ} \mathrm{C}(\mathrm{mPa} . \mathrm{s})$ & 82.54 & 15.31 & 7.43 & 7.85 & 3.37 \\
Density $\left(25^{\circ} \mathrm{C}\right)$ & 0.9091 & 0.8645 & 0.8550 & 0.8564 & 0.8085 \\
API degree & 23 & 31 & 33 & 32 & 42 \\
Saturates (wt\%) & 42.4 & 59.7 & 47.0 & 47.1 & 82.5 \\
Aromatics (wt\%) & 42.5 & 28.5 & 44.6 & 49.0 & 17.1 \\
Resins (wt\%) & 11.4 & 9.1 & 2.6 & 3.0 & 0.4 \\
Asphaltenes(wt\%) & 3.7 & 2.7 & 5.8 & 0.9 & 0.0 \\
\hline
\end{tabular}

\section{Results and discussion}

\subsection{Crude oil EACN determination by PIT measurements}

In EOR applications, a suitable description of the apparent hydrophobicity of the crude oil is needed in order to adapt the aqueous phase formulation injected (surfactant system and salinity) with the view to get a WIII microemulsion. In that way, the EACN concept is often used because it is simple to assess, it is specific to the oil and easy to use for correlations. The EACN is defined as the number of carbons of the linear alkane which presents a minimum of interfacial tension (optimum formulation) under the same conditions as the original oil in a given SOW system. Its use in the petroleum field is all the more important that it was first developed for mimicking crude oils by $n$-alkane mixtures [37].

It can be determined from correlation with fish diagrams of $n$-alkane [36] or from equilibrated salinity scans, which are both at equilibrium and time-consuming. Recently, EACN of crude oils have been predicted using machine learning models [38]. Our work highlights a new method to determine crude oil EACN thanks to PIT measurements. Indeed, in an SOW system with a defined surfactant, the PIT measured with $n$-alkanes are linearly correlated with their ACN (Alkane Carbon Number). Figure 2 shows the data obtained with $\mathrm{C}_{10} \mathrm{E}_{4} / n$-alkane $/ 10^{-2} \mathrm{M} \mathrm{NaCl}_{\mathrm{aq}}$ systems. The PIT measurements can be achieved either by conductivity or by viscosity.

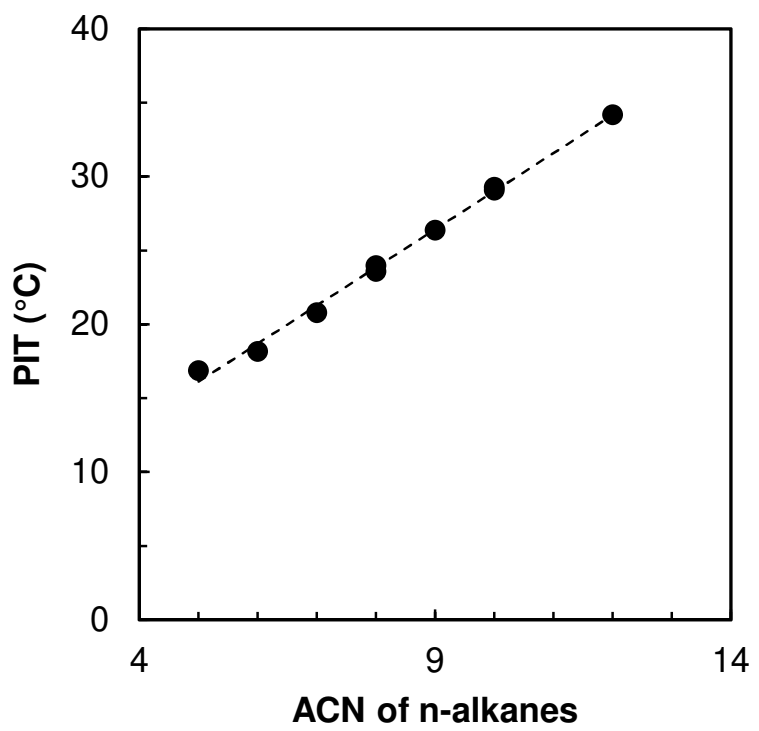

Figure 2 : Linear correlation between the PIT and the ACN of n-alkanes determined by conductivity and by viscosity measurements on $C_{10} E_{4} / n$-alkane $/ 10^{-2} \mathrm{M} \mathrm{NaCl}_{\text {aq }}$ systems, water weight fraction $=0.5$ 
Considering the results obtained, it is possible to determine a crude oil EACN by measuring the PIT of the $\mathrm{C}_{10} \mathrm{E}_{4} / \mathrm{Crude}$ oil/ $/ 10^{-2} \mathrm{M} \mathrm{NaCl}_{\text {aq }}$ system (Figures 3 and 4 ). The EACN of a crude oil is estimated by correlation with the ACN of $n$-alkanes. The curves obtained for some crude oils (A and B) present irregular shapes of conductivity compared to $n$-alkane curves. Nevertheless, the EACN values obtained are in the same range as those displayed in literature [37]. It is also important to be aware that the EACN depends on the surfactant used for its determination. Ideally, to be representative, the EACN should be determined with the same system of surfactants as the one used in the aqueous solution injected [39]. As mentioned also below, the viscosity and conductivity measurements present some discrepancies for crude oils D and E due to the lower precision of the viscosity PIT experiment (large area of minimum viscosity) compared to the conductivity one (PIT is the temperature at the conductivity fall).
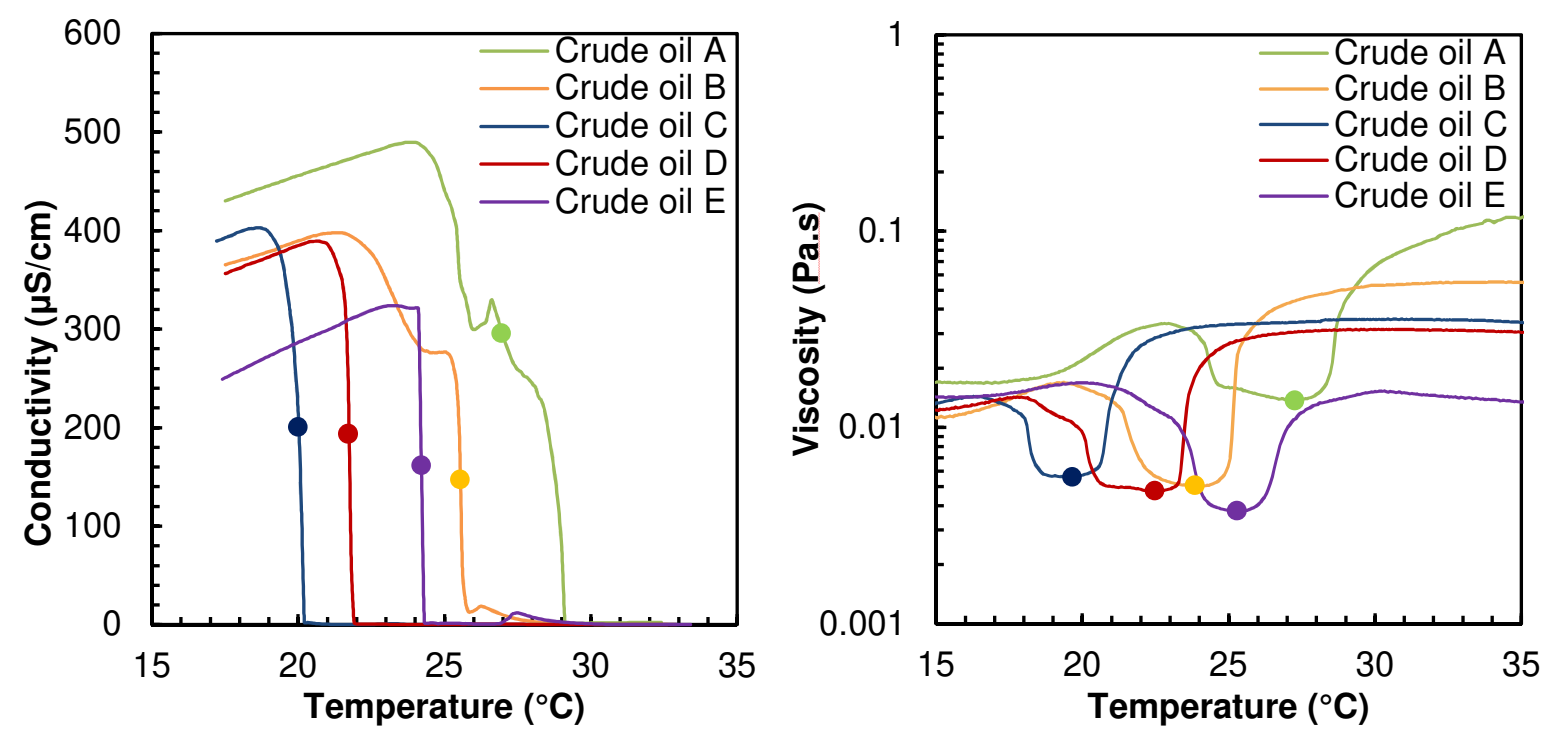

Figure 3 : Dynamic PIT measurements of crude oils A-E with $C_{10} E_{4}$ as surfactant by conductivity (Left) and viscosity (Right) on $\mathrm{C}_{10} \mathrm{E}_{4} /$ crude oils $/ 10^{-2} \mathrm{M} \mathrm{NaCl}_{\text {aq }}$ systems. The PIT values determined are displayed with dots

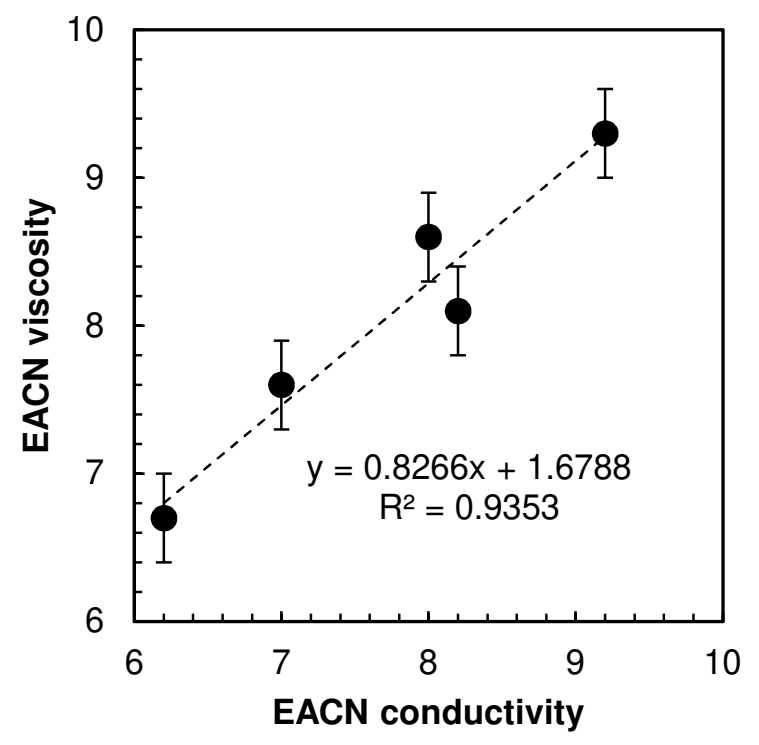

Figure 4 : EACN correlation for crude oils between conductivity and viscosity measurements 
Table 3 : EACN values of crude oils determined by conductivity and viscosity

\begin{tabular}{cccc}
\hline $\begin{array}{c}\text { Crude } \\
\text { oil }\end{array}$ & $\begin{array}{c}\text { EACN } \\
\text { conductivity }\end{array}$ & $\begin{array}{c}\text { EACN } \\
\text { viscosity }\end{array}$ & $\begin{array}{c}\text { Deviation } \\
(\boldsymbol{\%})\end{array}$ \\
\hline A & 9.2 & 9.3 & 1.1 \\
B & 8.2 & 8.1 & 1.1 \\
C & 6.2 & 6.7 & 7.5 \\
D & 7.0 & 7.6 & 7.9 \\
E & 8.0 & 8.6 & 7.0 \\
\hline
\end{tabular}

\subsection{Assessment of the amphiphilicity of EOR surfactants by the PIT-Slope method}

As mentioned before, the PIT can be precisely determined and expresses the amphiphilicity of the surfactant in its environment, including the contributions of oil hydrophobicity and water salinity. However, the PIT cannot be determined directly for SOW systems based solely on ionic surfactants, which are more hydrophilic than non-ionics. To characterize all surfactant types, it is better to measure the PIT variation induced by adding increasing amounts of the surfactant under study to a well-defined SOW reference system. The reference system used is $\mathrm{C}_{10} \mathrm{E}_{4} / n$-Octane $/ 10^{-2} \mathrm{M} \mathrm{NaCl}_{\text {aq }}$ because it shows a reproducible PIT close to room temperature $\left(23.9^{\circ} \mathrm{C}\right)$ [28]. This SOW system allowed an accurate characterization of numerous surfactants according to the so-called PIT-Slope method [40,41]. Figure 5 shows the conductivity profiles as a function of temperature for different added concentration of two illdefined surfactants to the $\mathrm{C}_{10} \mathrm{E}_{4}$ reference surfactant: the non-ionic Tween 85 surfactant and a classical propoxylated sulfated alcohol surfactant $\mathrm{nC}_{16-18} \mathrm{PO}_{4} \mathrm{SO}_{4} \mathrm{Na}$ from BASF (Table 4) as described in the literature [42]. Tween 85 produces a diminution of the PIT whereas the anionic surfactant increases the PIT. The increase of hydrophilicity due to the addition of the anionic surfactant is high and no more temperature-induced phase inversion is observed for concentrations over $0.380 \mathrm{wt} . \%$.
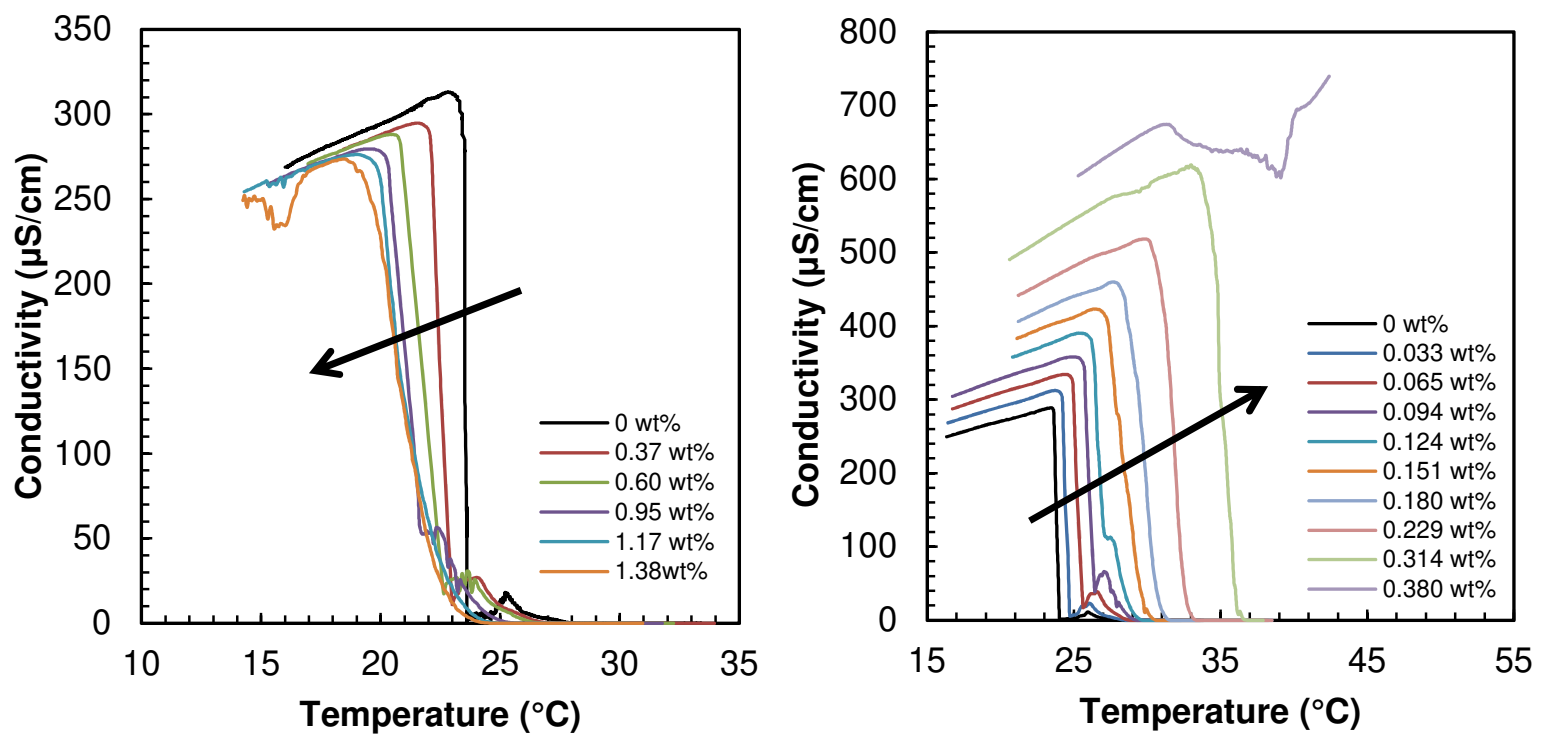

Figure 5 : (Left) Negative PIT variation due to addition of Tween 85 to the reference system (Right) Positive PIT variation due to addition of the propoxylated sulfated alcohol surfactant $n C_{16-}$ ${ }_{18} \mathrm{PO}_{4} \mathrm{SO}_{4} \mathrm{Na}$ to the reference system 
Table 4: Chemical structure of the Tween 85 , the $n C_{16-18} P_{4} O_{4} \mathrm{SO}_{4} \mathrm{Na}$ and the $\mathrm{C}_{10} \mathrm{E}_{4}$ surfactants

Trade name

To clearly identify the amphiphilicity of the surfactant under study, the variation of the PIT must be represented as a function of its molar fraction compared to the $\mathrm{C}_{10} \mathrm{E}_{4}$ reference surfactant as detailed below. Even if the added surfactants are complex mixtures, a mean molecular weight is taken to convert weight concentrations into molar concentrations.

$$
\text { Molar fraction } x=\frac{\text { Moles of added surfactant }}{\text { Moles of } C_{10} E_{4}+\text { Moles of added surfactant }}
$$

From the conductivity-temperature profiles, the relative amphiphilicity of the surfactant compared to $\mathrm{C}_{10} \mathrm{E}_{4}$ can be readily determined. If the slope of the PIT variation as a function of the molar fraction of the added surfactant is positive ( $\mathrm{dPIT} / \mathrm{dx}>0$ ), the surfactant added is more hydrophilic than $\mathrm{C}_{10} \mathrm{E}_{4}$. If this slope is negative $(\mathrm{dPIT} / \mathrm{dx}<0)$, the surfactant added is more hydrophobic than $\mathrm{C}_{10} \mathrm{E}_{4}$. The higher the PIT-Slope value is, the more hydrophilic the surfactant is.

Figure 6 shows the evolution of the PIT at different molar fractions of $\mathrm{nC}_{16-18} \mathrm{PO}_{4} \mathrm{SO}_{4} \mathrm{Na}$ surfactant. The experiment was repeated twice in order to demonstrate the reproducibility of this method. This evolution is clearly not linear for ionic surfactants [41], but in order to give a value of amphiphilicity to the surfactant, a linear correlation is assumed. The PIT-Slope value of a surfactant appears to be reproducible and specific to its amphiphilicity, even for ill-defined technical grade EOR surfactants that are complex mixtures (Figure 6 and Table 5). The margin of error obtained of $3.2 \%$ indicates that the method used can provide a clear hydrophilicity description of EOR surfactants.

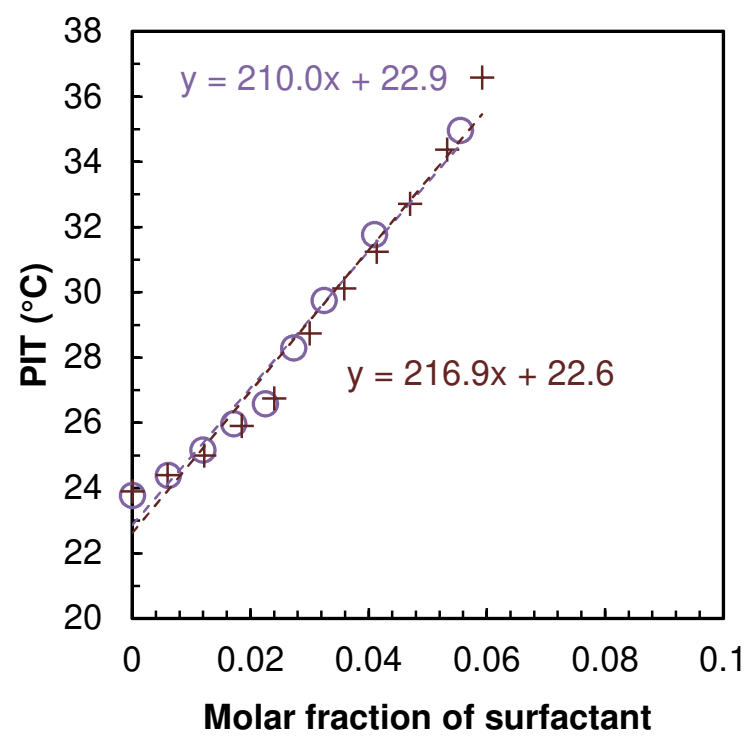

Figure 6: Repeatability of the PIT-Slope determination for the $n \mathrm{C}_{16-18} \mathrm{PO}_{4} \mathrm{SO}_{4} \mathrm{Na}$ surfactant 
Table 5: PIT-Slope values of several EOR surfactants

\begin{tabular}{lcc}
\hline EOR surfactant & Structure & $\begin{array}{l}\mathbf{d P I T} / \mathbf{d x} \\
\left({ }^{\circ} \mathbf{C}\right)\end{array}$ \\
\hline$n \mathrm{C}_{16-18} \mathrm{PO}_{7} \mathrm{EO}_{5} \mathrm{OCH}{ }_{2} \mathrm{COONa}$ & 503 \\
$n \mathrm{C}_{16-18} \mathrm{EO}_{10} \mathrm{OCH}_{2} \mathrm{COONa}$ & 493 \\
$n \mathrm{C}_{16-18} \mathrm{PO}_{2} \mathrm{SO}_{4} \mathrm{Na}$ & 274 \\
$n \mathrm{C}_{16-18} \mathrm{PO}_{4} \mathrm{SO}_{4} \mathrm{Na}$ & 213 \\
$\mathrm{iC}_{13} \mathrm{EO}_{13}$ & 168 \\
$\mathrm{iC}_{10} \mathrm{EO}_{10}$ & 139 \\
$\mathrm{iC}_{17} \mathrm{EO}_{12}$ & 122 \\
\hline
\end{tabular}

These different PIT-Slope values of EOR surfactants can be compared to the ones of well-defined surfactants already determined similarly in the previous years [40,41], with a view to classify them according to their amphiphilicity in a more refined manner that Griffin HLB [43] (Figure 7).

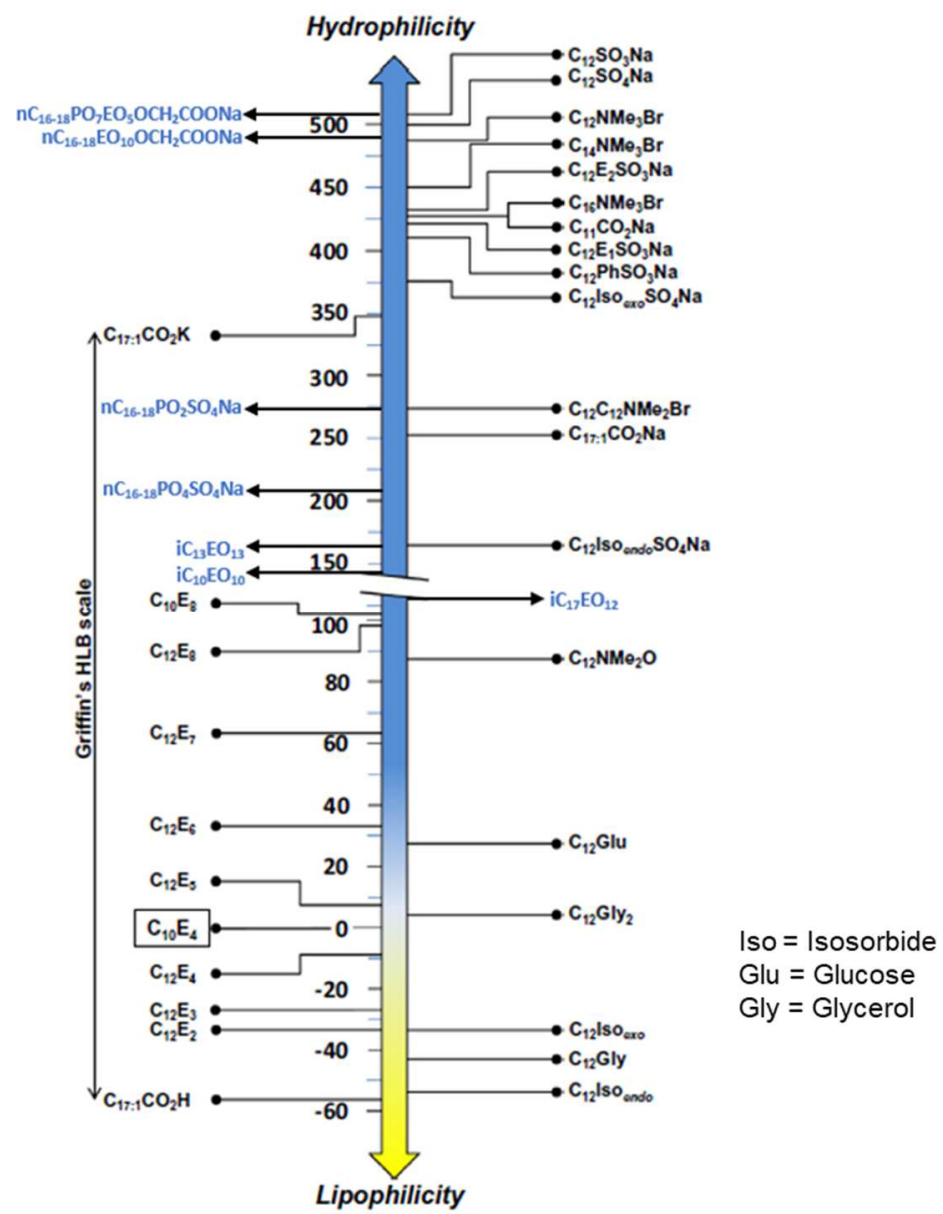

Figure 7 : PIT-Slope scale of well-defined (black) and EOR (blue) surfactants ( $E=E O=$ Ethoxylated groups) 
Additionally, for non-ionic surfactants, this method can be used to determine the value of the characteristic parameter of the surfactant ( $\beta$ or Cc) in the HLD equation as showed by Zarate et al. [44] with Tween 80, Tween 20 and Span 20 from our PIT vs concentration data. Ontiveros et al [45] proposed the following equation to correlate directly the PIT-slope and some parameters of the HLD with the PACN [46]:

$$
\frac{d P I T}{d x_{2}}=\frac{\beta_{r e f}-\beta_{2}}{c_{t 1}}=\frac{C c_{r e f}-C c}{c_{t 1}} \quad \text { or } \quad \frac{d P I T}{d x_{2}}=\frac{P A C N_{r e f}-P A C N_{2}}{c_{t 1} / k}
$$

The PACN is the preferred alkane carbon number, i.e. the oil that provides the optimum formulation at $25^{\circ} \mathrm{C}$ without alcohol or salt. The PACN of the reference system is 8 (octane) and the value of $\beta$ is 1.2 . PIT-slope values allows to get a preliminary good and fast estimation of HLD data that are normally obtained after an equilibration process.

However in EOR applications, surfactant systems are most of the time a mixture of different surfactants in order to adjust more easily the aqueous formulation to the salinity of injection water. Actually, the PIT-Slope values of individual surfactant can provide a relevant value of the amphiphilicity of EOR surfactant mixtures. Indeed, it is possible to predict the global value of a mixture of surfactants knowing the PIT-Slope value of each surfactant involved according to a linear mixing rule (Figure 8, Equation 7, and Table 6). In the first place, this model may appear questionable according to the interaction between surfactants polar heads already discussed in the literature [47-49].
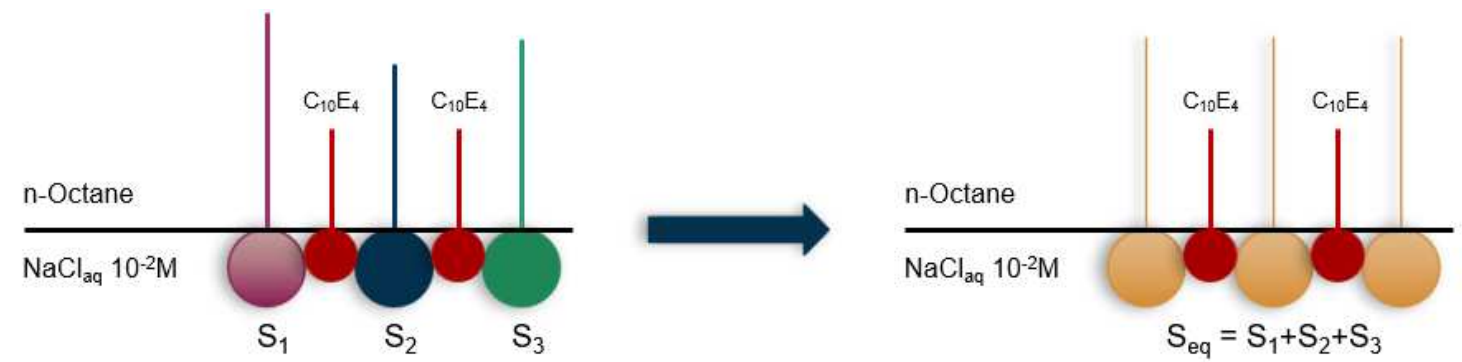

Figure 8 : Illustration of the predictive PIT-Slope model for surfactant mixture where $C_{10} E_{4}$ is the reference surfactant, $S_{1}, S_{2}$ and $S_{3}$ are individual non-ionic and anionic EOR surfactants, and $S_{\text {eq }}$ is the hypothetical surfactant equivalent to the mixture $S_{1}+S_{2}+S_{3}$

The PIT-Slope value of EOR surfactant mixtures is calculated from the individual PIT-slopes and the molar fractions $\mathrm{x}_{\mathrm{i}}$ of the different surfactants in the blend:

$$
\left(\frac{d P I T}{d x}\right)_{\text {mixture }}=\sum_{i=1}^{n}\left(x_{i}\left(\frac{d P I T}{d x}\right)_{i}\right)
$$

The following table 6 and figure 9 show the results obtained for the experimental and predicted PITSlope values for various EOR surfactant mixtures. 
Table 6: Experimental and predicted PIT-Slope values of EOR surfactant mixtures

\begin{tabular}{ccccc}
\hline EOR surfactant mixtures & $\begin{array}{c}\text { dPIT/dx } \\
\text { predicted }\end{array}$ & $\begin{array}{c}\text { dPIT/dx } \\
\text { experimental }\end{array}$ & $\begin{array}{c}\mathbf{M}_{\text {eq }} \\
(\mathbf{g} / \mathbf{m o l})\end{array}$ & $\begin{array}{c}\text { Deviation } \\
(\%)\end{array}$ \\
\hline$n \mathrm{C}_{16-18} \mathrm{PO}_{2} \mathrm{SO}_{4} \mathrm{Na}_{2}+\mathrm{nC}_{16-18} \mathrm{PO}_{4} \mathrm{SO}_{4} \mathrm{Na}+$ & 226 & 223 & 588 & 1.3 \\
$\mathrm{iC}_{13} \mathrm{EO}_{13}$ & 249 & 253 & 544 & 1.6 \\
$n \mathrm{C}_{16-18} \mathrm{PO}_{2} \mathrm{SO}_{4} \mathrm{Na}+\mathrm{iC}_{13} \mathrm{EO}_{13}$ & 199 & 202 & 639 & 1.5 \\
$n \mathrm{C}_{16-18} \mathrm{PO}_{4} \mathrm{SO}_{4} \mathrm{Na}+\mathrm{iC}_{13} \mathrm{EO}_{13}$ & 181 & 184 & 606 & 1.6 \\
$n \mathrm{C}_{16-18} \mathrm{PO}_{4} \mathrm{SO}_{4} \mathrm{Na}+\mathrm{iC}_{13} \mathrm{EO}_{10}$ & 187 & 196 & 593 & 4.6 \\
$n \mathrm{C}_{16-18} \mathrm{PO}_{4} \mathrm{SO}_{4} \mathrm{Na}+\mathrm{iC}_{10} \mathrm{EO}_{10}$ & 186 & 176 & 643 & 5.4 \\
$n \mathrm{C}_{16-18} \mathrm{PO}_{4} \mathrm{SO}_{4} \mathrm{Na}+\mathrm{iC}_{17} \mathrm{EO}_{12}$ & 14,1 & 26,1 & 114 & 46.0 \\
$n \mathrm{C}_{16-18} \mathrm{PO}_{4} \mathrm{SO}_{4} \mathrm{Na}+2-\mathrm{BuOH}$ & 31,1 & 45,2 & 155 & 31.2 \\
\hline$n \mathrm{C}_{16-18} \mathrm{PO}_{7} \mathrm{EO}_{5} \mathrm{OCH}_{2} \mathrm{COONa}+\mathrm{iC}_{13} \mathrm{EO}_{13}$ & 248 & 287 & 875 & 13.6 \\
$n \mathrm{C}_{16-18} \mathrm{PO}_{7} \mathrm{EO}_{10} \mathrm{OCH}_{2} \mathrm{COONa}+\mathrm{iC}_{10} \mathrm{EO}_{10}$ & 214 & 224 & 814 & 4.5 \\
$n \mathrm{C}_{16-18} \mathrm{PO}_{7} \mathrm{EO}_{10} \mathrm{OCH}_{2} \mathrm{COONa}+\mathrm{iC}_{17} \mathrm{EO}_{12}$ & 216 & 217 & 911 & 0.5 \\
\hline
\end{tabular}

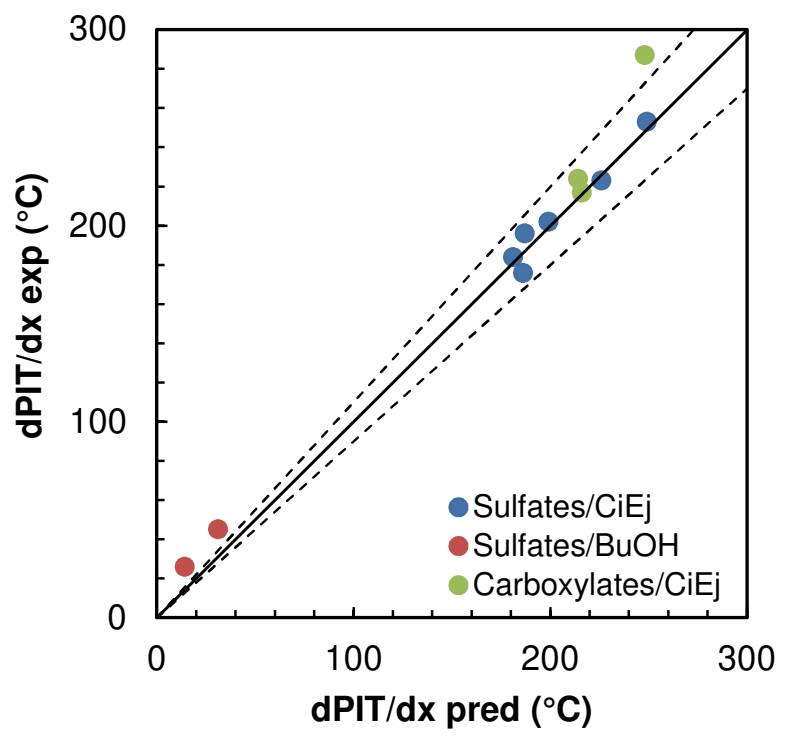

Figure 9 : Experimental vs predicted PIT-Slope values of surfactant mixtures with the $10 \%$ margin of error (dotted lines)

As shown in figure 9, the linear model applied to the PIT-Slope leads to a pretty good correlation between experimental and predicted values. The most significant deviations to the model occur with one system carboxylates $/ \mathrm{C}_{\mathrm{i}} \mathrm{EO}_{\mathrm{j}}$ and two systems sulfates $/ 2-\mathrm{BuOH}$. In this last case, the deviation is expected because 2-butanol is an amphiphilic solvent which partitions itself between the oil phase and the interfacial film. Therefore, only a part of the added butanol is localized at the interface and as the sulfate surfactant is more hydrophilic than butanol, the measured PIT-Slopes are higher than the predicted ones. Accordingly, the linear mixing rule based on molar fractions (Equation 7) appears to be relevant to predict the PIT-Slope values of mixture of technical grade ionic and non-ionic surfactants used in EOR applications. The PIT-slope method is also accurate whatever the type of surfactants used in EOR with a percentage of error of $\pm 8.4 \%$ for non-ionic surfactants, $\pm 9.0 \%$ for ionic ones and $\pm 7.5 \%$ for ionic/nonionic surfactant mixtures. 


\subsection{Tracking the optimum formulation by the PIT}

The phase inversion of emulsion is closely related to the formation of a WIII microemulsion system at equilibrium as demonstrated by Shinoda et al for non-ionic surfactants [27] and later by Salager et al for ionic surfactants [50]. The PIT determination could thus be an effective and fast method for tracking the formation of WIII microemulsion with crude oils. Traditionally, the optimum formulation of a petroleum system is determined at equilibrium by varying the salinity at a constant temperature equal to the reservoir temperature. For tracking the optimum formulation with the PIT, the reverse experiment is performed. Instead of maintaining the temperature constant, the salinity is kept constant and the temperature is the variable parameter. The PIT is now considered as the theoretical reservoir temperature associated to the fixed optimum salinity of the system. The phase inversion experiments were carried out first with one particular crude oil (B) and different EOR surfactant systems previously characterized with the PIT-Slope method (Figure 10 and Table 7). The results obtained show that the shape of the PIT signal is closely associated to the phase behavior of the petroleum system tested. For a "clean" profile of inversion, the petroleum system tested exhibits a WIII at the PIT. In the case of an incomplete or fluctuating inversion, the system does not provide a WIII at the PIT (systems E and F in Figure 10 and 11). It is also important to have a concentration of the surfactant which must be slightly higher than the minimal concentration needed to get the first WIII system at equilibrium. If the concentration is close to this critical value, the conductivity profile is similar to those observed for the formulations $\mathrm{E}$ and $\mathrm{F}$ as reported by Pizzino et al [28]. Therefore, the shapes of the conductivity profiles can be considered as a relevant descriptor to infer the formation or not of a WIII with a given EOR surfactant/Crude oil/Water system at a given temperature.

Figure 10 shows that the surfactant system has an important influence on the PIT shifts and shapes. Indeed, the PIT shift is correlated with the hydrophilicity of the surfactant system. The more hydrophilic the surfactant system is, the higher the PIT is and vice versa. It is therefore possible to correlate the PIT values obtained for a same crude oil with the PIT-Slope values of each surfactant systems used (Figure 10, right). The results highlight also a possible limit temperature below which the system cannot form a WIII microemulsion. The PIT-Slope method proves its efficiency not only to quantify the amphiphilicity of EOR surfactant systems, but also to estimate the dynamic PIT and the optimum formulation of petroleum systems using alkyl-propoxylated sodium sulfate $/ \mathrm{C}_{\mathrm{i}} \mathrm{E}_{\mathrm{j}}$ mixtures.
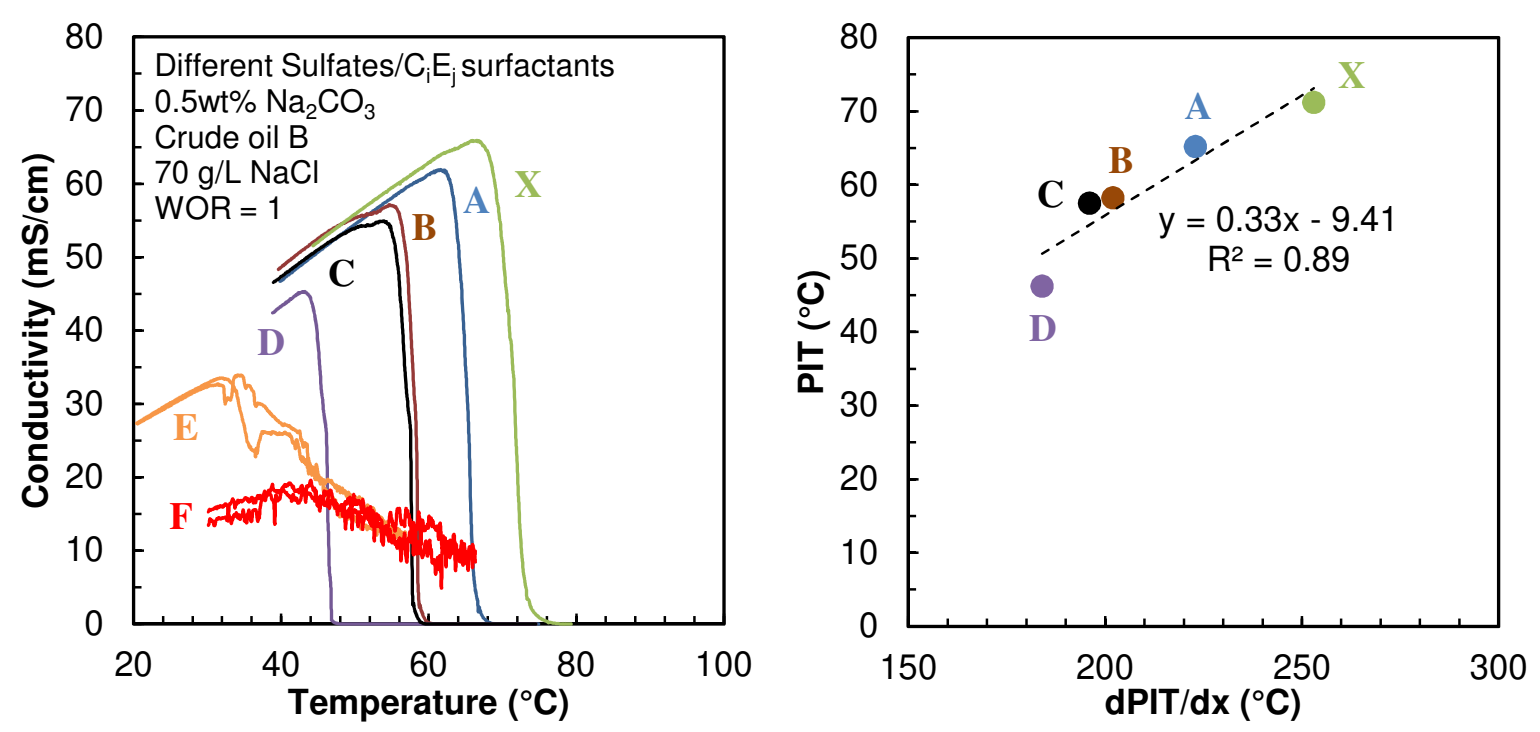

Figure 10 : (Left) Dynamic PIT measurements of crude oil B with $70 \mathrm{~g} / \mathrm{L} \mathrm{NaCl}$ and different Sulfates $/ C_{i} E_{j}$ surfactants at WOR $=1,($ Right) Correlation between PIT and PIT-Slope values of EOR surfactant systems used with the same crude oil B 
Table 7: Experimental PIT values and WIII presence obtained for the previous study with crude oil B (Figure 14)

\begin{tabular}{cccc}
\hline Mixture name & Surfactant system & PIT $\left({ }^{\circ} \mathbf{C}\right)$ & WIII \\
\hline $\mathbf{X}$ & $n \mathrm{C}_{16-18} \mathrm{PO}_{2} \mathrm{SO}_{4} \mathrm{Na}+\mathrm{iC}_{13} \mathrm{EO}_{13}$ & 71.2 & Yes \\
$\mathbf{A}$ & $n \mathrm{C}_{16-18} \mathrm{PO}_{2} \mathrm{SO}_{4} \mathrm{Na}_{2} \mathrm{nC}_{16-18} \mathrm{PO}_{4} \mathrm{SO}_{4} \mathrm{Na}+\mathrm{iC}_{13} \mathrm{EO}_{13}$ & 65.2 & Yes \\
$\mathbf{B}$ & $n \mathrm{C}_{16-18} \mathrm{PO}_{4} \mathrm{SO}_{4} \mathrm{Na}+\mathrm{iC}_{13} \mathrm{EO}_{13}$ & 58.2 & Yes \\
$\mathbf{C}$ & $n \mathrm{C}_{16-18} \mathrm{PO}_{4} \mathrm{SO}_{4} \mathrm{Na}+\mathrm{iC}_{10} \mathrm{EO}_{10}$ & 57.5 & Yes \\
$\mathbf{D}$ & $n \mathrm{C}_{16-18} \mathrm{PO}_{4} \mathrm{SO}_{4} \mathrm{Na}+\mathrm{iC}_{13} \mathrm{EO}_{10}$ & 46.2 & Yes \\
$\mathbf{E}$ & $n \mathrm{C}_{16-18} \mathrm{PO}_{4} \mathrm{SO}_{4} \mathrm{Na}+\mathrm{iC}_{17} \mathrm{EO}_{12}$ & $\mathrm{NA}$ & No \\
$\mathbf{F}$ & $n \mathrm{C}_{16-18} \mathrm{PO}_{4} \mathrm{SO}_{4} \mathrm{Na}+2-\mathrm{BuOH}$ & $\mathrm{NA}$ & No \\
\hline
\end{tabular}

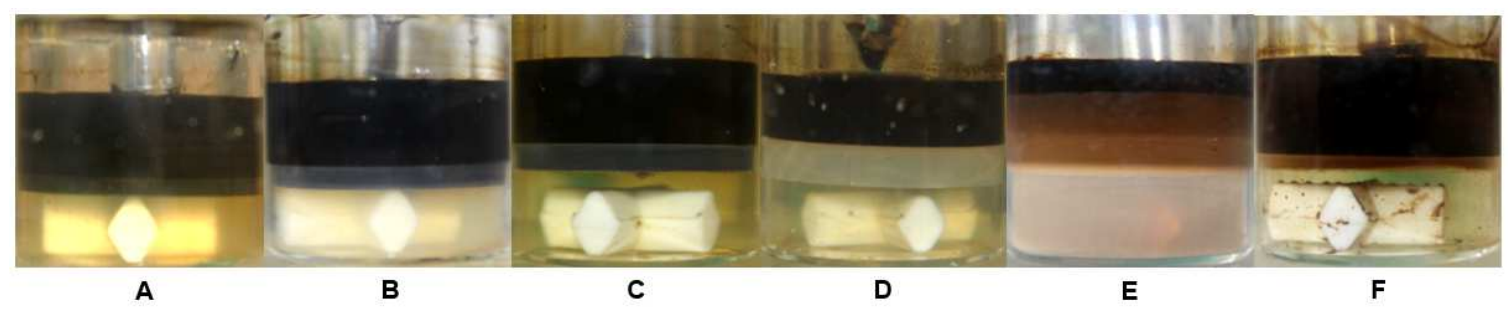

Figure 11 : Pictures of well-defined WIII (A-D) and ill-defined systems $(E-F)$ obtained at the PIT after 1 day equilibration with surfactant mixtures described in Table 7 and with the same crude oil $B$

Even if the PIT can be an effective method to find the optimum formulation, in EOR applications the salinity remains the adjustable parameter to reach the WIII microemulsion system inside the reservoir. Fortunately, the PIT can be correlated with the salinity of the aqueous phase at a logarithmic scale for a defined surfactant and oil used (Figure 12) according to the HLD equation in case of ionic surfactants displayed below [10].

$$
H L D=\sigma+\ln (S)-k \cdot E A C N+t . \Delta T+f(A)
$$

The " $\sigma$ " parameter for ionic surfactants (or $\beta$ for non-ionic) in the HLD equation is also called characteristic curvature (Cc) by Acosta's group in the HLD-NAC model as described in the introduction. It has been shown that the HLD equation including the characteristic curvature is really useful to predict the optimum formulation as shown in particular by the recent work of Nguyen et al [51]. In this study, the Cc parameter is used to classify the surfactant toward their salinity affinities as well as providing the salinity area in which the surfactant provide ultralow interfacial tension with tetradecane.

Considering our method, at the optimum formulation, the HLD equation is equal to 0 and without alcohol and considering the PIT as the reservoir temperature the equation become as follow.

$$
P I T=-\frac{1}{t} \ln \left(S^{*}\right)+\frac{k \cdot E A C N-\sigma}{t}+25 \text { with } \mathrm{f}(\mathrm{A})=0 \text { and } \Delta \mathrm{T}=\mathrm{PIT}-25
$$

For these experiments, different crude oils were used with the same surfactant system. In the same way, for each SOW system, different aqueous phase salinities were fixed and the associated PIT was measured. For each sample, the system was left at equilibrium during 1 day at the PIT in order to observe the presence or not of a WIII microemulsion system. 
The classical HLD equation for ionic surfactants assumes a correlation between the PIT and the logarithm of the aqueous salinity which is in agreement with our results displayed in figure 12 . However, the slope is different for the three crude oils, even if the surfactant system remains the same, which is not in agreement with the HLD equation. A possible explanation of this phenomenon is the insertion within the interfacial film of crude oil endogenous surfactants revealed by addition of $\mathrm{Na}_{2} \mathrm{CO}_{3}$ as described in the literature [52,53] and which are not taken into account in the HLD model. Deviations from ionic HLD equation is also justified by the nature of the mixture that contains both anionic and non-ionic surfactants, and also by the non-ideal behaviour of these mixtures which is extensively reported in literature $[47,54,55]$.

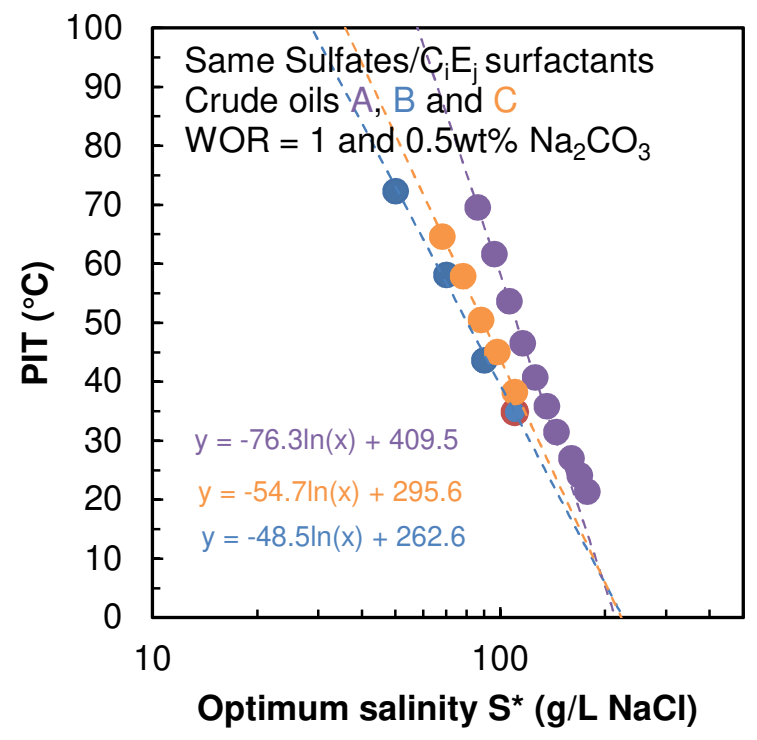

Figure 12 : Correlation between dynamic PIT and aqueous phase optimum salinity for different crude oils with the same surfactant system (points surrounded in red: there is no WIII at equilibrium)

The PIT determination at different salinities allows a fast screening of surfactant formulations in order to select the best candidates regarding PIT shifts and shapes. Knowing the reservoir temperature, the optimum salinity can be easily deduced from figure 12 , in a reliable and faster way than equilibrated systems

\section{Conclusions}

In this work, a new method is described to characterize EOR formulations by determining dynamic Phase Inversion Temperatures (PIT). The PIT, initially described for systems based on ethoxylated nonionic surfactants, proves to be relevant for systems based on non-ionic/ionic surfactants mixtures too. The PIT-Slope method allows evaluating the amphiphilicity of surfactants and their mixtures with a view to classify them for EOR applications. The PIT-Slope values of surfactant mixtures are also predictable by a linear mixing rule of the PIT-Slope values of individual surfactants.. Aside the surfactant system, the PIT also allows a fast crude oil EACN determination by correlation with ACN of $n$-alkanes.

Finally, the PIT can be also used to determine the optimum formulation of crude oil based systems. By analyzing the conductivity profiles during a phase inversion experiment, it is possible to predict the formation or not of WIII microemulsions at equilibrium. The phase inversion of petroleum system establishes new correlations between optimum salinity and the PIT-Slope values of surfactants, which can be in the future enriched with other parameters specific to surfactants [56-58] and crude oils [59] in order to suggest better predictions. 
The strength of this experiment remains the rapid evaluation of the presence of WIII microemulsion, which allows performing preliminary screening of EOR formulations to find the best surfactant system for one particular crude oil. This method to reach the optimum formulation has a great potential regarding the EOR field and can be carried out in conjunction with predictive EOR models already introduced in the literature [23,60-65].

\section{Acknowledgments}

The authors would like to thank TOTAL for financing this work and for allowing its publication. BASF is also thanked for providing the surfactant samples.

We would also like to thank Maurice BOURREL and Nicolas PASSADE-BOUPAT for the helping discussions about petroleum phase behavior, EOR surfactant formulations and microemulsion correlations, which have provided a great contribution to this study.

Chevreul Institute (FR 2638), Ministère de l'Enseignement Supérieur et de la Recherche, Région NordPas de Calais and FEDER are also acknowledged for supporting this work.

\section{Conflict of interest}

The authors declare that they have no conflict of interest.

\section{References}

[1] D. Levitt, A. Jackson, C. Heinson, L.N. Britton, T. Malik, V. Dwarakanath, G.A. Pope, Identification and Evaluation of High-Performance EOR Surfactants, in: SPE/DOE Symposium on Improved Oil Recovery, Society of Petroleum Engineers, Tulsa, Oklahoma, USA, 2006. doi:10.2118/100089-MS.

[2] A. Flaaten, Q.P. Nguyen, G.A. Pope, J. Zhang, A Systematic Laboratory Approach to Low-Cost, High-Performance Chemical Flooding, in: SPE Symposium on Improved Oil Recovery, Society of Petroleum Engineers, Tulsa, Oklahoma, USA, 2008. doi:10.2118/113469-MS.

[3] P. Zhao, A. Jackson, C. Britton, D.H. Kim, L.N. Britton, D. Levitt, G.A. Pope, Development of High-Performance Surfactants for Difficult Oils, in: SPE Symposium on Improved Oil Recovery, Society of Petroleum Engineers, Tulsa, Oklahoma, USA, 2008. doi:10.2118/113432-MS.

[4] M. Bourrel, C. Chambu, The Rules for Achieving High Solubilization of Brine and Oil by Amphiphilic Molecules, Society of Petroleum Engineers Journal. 23 (1983) 327-338. doi:10.2118/10676-PA.

[5] M. Bourrel, R.S. Schechter, Microemulsion and Related Systems: Formulation, Solvency, and Physical Properties (Surfactant and Science Series, Vol. 30), Marcel and Dekker, New York. (1988).

[6] M.Á. Rodríguez-Valverde, M. Tirado Miranda, Derivation of Jurin's law revisited, European Journal of Physics. 32 (2011) 49-54. doi:10.1088/0143-0807/32/1/005.

[7] D.W. Green, G.P. Willhite, Enhanced oil recovery, Second edition, Society of Petroleum Engineers, Richardson, Texas, USA, 2018.

[8] M.J. Rosen, J.T. Kunjappu, Surfactants and interfacial phenomena, 4th ed, Wiley, Hoboken, N.J, 2012. 
[9] J.H. Schulman, W. Stoeckenius, L.M. Prince, Mechanism of Formation and Structure of Micro Emulsions by Electron Microscopy, The Journal of Physical Chemistry. 63 (1959) 1677-1680. doi:10.1021/j150580a027.

[10] J.-L. Salager, R.E. Antón, J.M. Anderez, J.-M. Aubry, Formulation des micro-émulsions par la méthode HLD, Techniques de l'Ingénieur. 157 (2001) 2001.

[11] R.N. Healy, R.L. Reed, D.G. Stenmark, Multiphase Microemulsion Systems, Society of Petroleum Engineers Journal. 16 (1976) 147-160. doi:10.2118/5565-PA.

[12] C. Huh, Interfacial tensions and solubilizing ability of a microemulsion phase that coexists with oil and brine, Journal of Colloid and Interface Science. 71 (1979) 408-426. doi:10.1016/0021-9797(79)90249-2.

[13] L.A. Verkruyse, S.J. Salter, Potential Use of Nonionic Surfactants in Micellar Flooding, in: SPE Oilfield and Geothermal Chemistry Symposium, Society of Petroleum Engineers, Phoenix, Arizona, 1985. doi:10.2118/13574-MS.

[14] A. Graciaa, L.N. Fortney, R.S. Schechter, W.H. Wade, S. Yiv, Criteria for Structuring Surfactants To Maximize Solubilization of Oil and Water: Part 1-Commercial Nonionics, Society of Petroleum Engineers Journal. 22 (1982) 743-749. doi:10.2118/9815-PA.

[15] Y. Barakat, L.N. Fortney, R.S. Schechter, W.H. Wade, S.H. Yiv, A. Graciaa, Criteria for structuring surfactants to maximize solubilization of oil and water, Journal of Colloid and Interface Science. 92 (1983) 561-574. doi:10.1016/0021-9797(83)90177-7.

[16] D. Langevin, D. Guest, J. Meunier, Correlation between interfacial tension and microemulsion structure in winsor equilibria. Role of the surfactant film curvature properties, Colloids and Surfaces. 19 (1986) 159-170. doi:10.1016/0166-6622(86)80333$\mathrm{X}$.

[17] J.-L. Salager, A.M. Forgiarini, L. Márquez, L. Manchego, J. Bullón, How to Attain an Ultralow Interfacial Tension and a Three-Phase Behavior with a Surfactant Formulation for Enhanced Oil Recovery: A Review. Part 2. Performance Improvement Trends from Winsor's Premise to Currently Proposed Inter- and Intra-Molecular Mixtures, J Surfact Deterg. 16 (2013) 631-663. doi:10.1007/s11743-013-1485-x.

[18] E. Acosta, E. Szekeres, D.A. Sabatini, J.H. Harwell, Net-Average Curvature Model for Solubilization and Supersolubilization in Surfactant Microemulsions, Langmuir. 19 (2003) 186-195. doi:10.1021/la026168a.

[19] J.L. Salager, J.C. Morgan, R.S. Schechter, W.H. Wade, E. Vasquez, Optimum Formulation of Surfactant/Water/Oil Systems for Minimum Interfacial Tension or Phase Behavior, Society of Petroleum Engineers Journal. 19 (1979) 107-115. doi:10.2118/7054PA.

[20] P.G. De Gennes, C. Taupin, Microemulsions and the flexibility of oil/water interfaces, J. Phys. Chem. 86 (1982) 2294-2304. doi:10.1021/j100210a011.

[21] E.J. Acosta, The HLD-NAC equation of state for microemulsions formulated with nonionic alcohol ethoxylate and alkylphenol ethoxylate surfactants, Colloids and Surfaces A: Physicochemical and Engineering Aspects. 320 (2008) 193-204. doi:10.1016/j.colsurfa.2008.01.049.

[22] E.J. Acosta, S.K. Kiran, C.E. Hammond, The HLD-NAC Model for Extended Surfactant Microemulsions, J Surfact Deterg. 15 (2012) 495-504. doi:10.1007/s11743-012-1343-2.

[23] L. Jin, A. Jamili, Z. Li, J. Lu, H. Luo, B.J. Ben Shiau, M. Delshad, J.H. Harwell, Physics based HLD-NAC phase behavior model for surfactant/crude oil/brine systems, Journal of Petroleum Science and Engineering. 136 (2015) 68-77. doi:10.1016/j.petrol.2015.10.039.

[24] L. Jin, M. Budhathoki, A. Jamili, Z. Li, H. Luo, B.J. Ben Shiau, M. Delshad, J.H. Harwell, Predicting microemulsion phase behavior using physics based HLD-NAC equation of state for surfactant flooding, Journal of Petroleum Science and Engineering. 151 (2017) 213-223. doi:10.1016/j.petrol.2016.12.035. 
[25] S. Ghosh, R.T. Johns, A Modified HLD-NAC Equation of State To Predict Alkali/Surfactant/Oil/Brine Phase Behavior, SPE Journal. 23 (2018) 550-566. doi:10.2118/175132-PA.

[26] K. Shinoda, H. Arai, The Correlation between Phase Inversion Temperature In Emulsion and Cloud Point in Solution of Nonionic Emulsifier, The Journal of Physical Chemistry. 68 (1964) 3485-3490. doi:10.1021/j100794a007.

[27] K. Shinoda, H. Kunieda, Conditions to produce so-called microemulsions: Factors to increase the mutual solubility of oil and water by solubilizer, Journal of Colloid and Interface Science. 42 (1973) 381-387. doi:10.1016/0021-9797(73)90303-2.

[28] A. Pizzino, V. Molinier, M. Catté, J.F. Ontiveros, J.-L. Salager, J.-M. Aubry, Relationship between Phase Behavior and Emulsion Inversion for a Well-Defined Surfactant $\left(\mathrm{C}_{10} \mathrm{E}_{4}\right.$ )/ $n$-Octane/Water Ternary System at Different Temperatures and Water/Oil Ratios, Industrial \& Engineering Chemistry Research. 52 (2013) 4527-4538. doi:10.1021/ie302772u.

[29] C. Pierlot, J.F. Ontiveros, M. Catté, J.-L. Salager, J.-M. Aubry, Cone-Plate Rheometer as Reactor and Viscosity Probe for the Detection of Transitional Phase Inversion of Brij30Isopropyl Myristate-Water Model Emulsion, Industrial \& Engineering Chemistry Research. 55 (2016) 3990-3999. doi:10.1021/acs.iecr.6b00399.

[30] J.L. Salager, M. Mi^ana-Pérez, J.M. Andérez, J.L. Grosso, C.I. Rojas, I. Layrisse, S.A. Intevep, Surfactant-oil-water systems near the affinity inversion part II: Viscosity of emulsified systems, Journal of Dispersion Science and Technology. 4 (1983) 161-173. doi:10.1080/01932698308943361.

[31] J.L. Salager, Surfactants in solution, M. Dekker, New York, 1996.

[32] L.-I. Tolosa, A. Forgiarini, P. Moreno, J.-L. Salager, Combined Effects of Formulation and Stirring on Emulsion Drop Size in the Vicinity of Three-Phase Behavior of Surfactant-Oil Water Systems, Industrial \& Engineering Chemistry Research. 45 (2006) 3810-3814. doi:10.1021/ie060102j.

[33] A. Standard, Standard test method for acid number of petroleum products by potentiometric titration-ASTM D 664-11A, ASTM International, West Conshohocken, PA. (2011).

[34] A. D2896, Standard Test Method for Base Number of Petroleum Products by Potentiometric Perchloric Acid Titration, Annual Book of Standards. (2007).

[35] N. Passade-Boupat, H. Zhou, M. Rondon-Gonzalez, Asphaltene Precipitation From Crude Oils : How To Predict It And To Anticipate Treatment?, in: SPE Middle East Oil and Gas Show and Conference, Society of Petroleum Engineers, Manama, Bahrain, 2013. doi:10.2118/164184-MS.

[36] S. Queste, J.L. Salager, R. Strey, J.M. Aubry, The EACN scale for oil classification revisited thanks to fish diagrams, Journal of Colloid and Interface Science. 312 (2007) 98107. doi:10.1016/j.jcis.2006.07.004.

[37] J.L. Cayias, R.S. Schechter, W.H. Wade, Modeling Crude Oils for Low Interfacial Tension, Society of Petroleum Engineers Journal. 16 (1976) 351-357. doi:10.2118/5813PA.

[38] B. Creton, I. Lévêque, F. Oukhemanou, Equivalent alkane carbon number of crude oils: A predictive model based on machine learning, Oil \& Gas Science and Technology Revue d'IFP Energies Nouvelles. 74 (2019) 30. doi:10.2516/ogst/2019002.

[39] L. Chang, G.A. Pope, S.H. Jang, M. Tagavifar, Prediction of microemulsion phase behavior from surfactant and co-solvent structures, Fuel. 237 (2019) 494-514. doi:10.1016/j.fuel.2018.09.151.

[40] J.F. Ontiveros, C. Pierlot, M. Catté, V. Molinier, J.-L. Salager, J.-M. Aubry, A simple method to assess the hydrophilic lipophilic balance of food and cosmetic surfactants using 
the phase inversion temperature of $\mathrm{C} 10 \mathrm{E} 4 / \mathrm{n}$-octane/water emulsions, Colloids and Surfaces A: Physicochemical and Engineering Aspects. 458 (2014) 32-39. doi:10.1016/j.colsurfa.2014.02.058.

[41] J.F. Ontiveros, C. Pierlot, M. Catté, V. Molinier, J.-L. Salager, J.-M. Aubry, Structureinterfacial properties relationship and quantification of the amphiphilicity of well-defined ionic and non-ionic surfactants using the PIT-slope method, Journal of Colloid and Interface Science. 448 (2015) 222-230. doi:10.1016/j.jcis.2015.02.028.

[42] J. Chen, X. Hu, Y. Fang, G. Jin, Y. Xia, What dominates the interfacial properties of extended surfactants: Amphipathicity or surfactant shape?, Journal of Colloid and Interface Science. 547 (2019) 190-198. doi:10.1016/j.jcis.2019.04.002.

[43] W.C. Griffin, Classification of surface-active agents by" HLB", J. Soc. Cosmet. Chem. 1 (1949) 311-326.

[44] S. Zarate-Muñoz, F. Texeira de Vasconcelos, K. Myint-Myat, J. Minchom, E. Acosta, A Simplified Methodology to Measure the Characteristic Curvature (Cc) of Alkyl Ethoxylate Nonionic Surfactants, J Surfact Deterg. 19 (2016) 249-263. doi:10.1007/s11743-0161787-x.

[45] J.F. Ontiveros, C. Pierlot, M. Catté, J.-L. Salager, J.-M. Aubry, Determining the Preferred Alkane Carbon Number (PACN) of nonionic surfactants using the PIT-slope method, Colloids and Surfaces A: Physicochemical and Engineering Aspects. 536 (2018) 30-37. doi:10.1016/j.colsurfa.2017.08.002.

[46] J.-L. Salager, A.M. Forgiarini, J. Bullón, How to Attain Ultralow Interfacial Tension and Three-Phase Behavior with Surfactant Formulation for Enhanced Oil Recovery: A Review. Part 1. Optimum Formulation for Simple Surfactant-Oil-Water Ternary Systems, J Surfact Deterg. 16 (2013) 449-472. doi:10.1007/s11743-013-1470-4.

[47] G. Rauwel, L. Leclercq, J. Criquelion, J.-M. Aubry, V. Nardello-Rataj, Aqueous mixtures of di-n-decyldimethylammonium chloride/polyoxyethylene alkyl ether: Dramatic influence of tail/tail and head/head interactions on co-micellization and biocidal activity, Journal of Colloid and Interface Science. 374 (2012) 176-186. doi:10.1016/j.jcis.2012.02.006.

[48] T. Lukowicz, R. Company Maldonado, V. Molinier, J.-M. Aubry, V. Nardello-Rataj, Fragrance solubilization in temperature insensitive aqueous microemulsions based on synergistic mixtures of nonionic and anionic surfactants, Colloids and Surfaces A: Physicochemical and Engineering Aspects. 458 (2014) 85-95. doi:10.1016/j.colsurfa.2013.11.024.

[49] B. Hong, L. Leclercq, M. Collinet-Fressancourt, J. Lai, P. Bauduin, J.-M. Aubry, V. Nardello-Rataj, Synergy between bis(dimethyldioctylammonium) molybdate and tetraethylene glycol monooctyl ether: A winning combination for interfacial catalysis in thermo-controlled and switchable microemulsions, Journal of Molecular Catalysis A: Chemical. 397 (2015) 142-149. doi:10.1016/j.molcata.2014.11.003.

[50] J.L. Salager, I. Loaiza-Maldonado, M. Minana-Perez, F. Silva, Surfactant-oil-water systems near the affinity inversion part I: Relationship between equilibrium phase behavior and emulsion type and stability, Journal of Dispersion Science and Technology. 3 (1982) 279-292. doi:10.1080/01932698208943642.

[51] T.T. Nguyen, C. Morgan, L. Poindexter, J. Fernandez, Application of the HydrophilicLipophilic Deviation Concept to Surfactant Characterization and Surfactant Selection for Enhanced Oil Recovery, J Surfactants Deterg. (2019) jsde.12305. doi:10.1002/jsde.12305.

[52] R. Varadaraj, C. Brons, Molecular Origins of Crude Oil Interfacial Activity Part 3: Characterization of the Complex Fluid Rag Layer Formed at Crude Oil-Water Interfaces, Energy \& Fuels. 21 (2007) 1617-1621. doi:10.1021/ef0606299. 
[53] R. Varadaraj, C. Brons, Molecular Origins of Crude Oil Interfacial Activity. Part 4: OilWater Interface Elasticity and Crude Oil Asphaltene Films, Energy \& Fuels. 26 (2012) 7164-7169. doi:10.1021/ef300830f.

[54] R.E. Antón, J.M. Andérez, C. Bracho, F. Vejar, J.-L. Salager, Practical Surfactant Mixing Rules Based on the Attainment of Microemulsion-Oil-Water Three-Phase Behavior Systems, in: R. Narayanan (Ed.), Interfacial Processes and Molecular Aggregation of Surfactants, Springer Berlin Heidelberg, Berlin, Heidelberg, 2008: pp. 83-113. doi:10.1007/12_2008_163.

[55] M.A. Arandia, A.M. Forgiarini, J.-L. Salager, Resolving an Enhanced Oil Recovery Challenge: Optimum Formulation of a Surfactant-Oil-Water System Made Insensitive to Dilution, Journal of Surfactants and Detergents. 13 (2010) 119-126. doi:10.1007/s11743009-1171-1.

[56] G. Hirasaki, C.A. Miller, M. Puerto, Recent Advances in Surfactant EOR, SPE Journal. 16 (2011) 889-907. doi:10.2118/115386-PA.

[57] J.R. Barnes, H. Dirkzwager, J. Smit, J. Smit, A. On, R.C. Navarrete, B. Ellison, M.A. Buijse, Application of Internal Olefin Sulfonates and Other Surfactants to EOR. Part 1: Structure - Performance Relationships for Selection at Different Reservoir Conditions, in: SPE Improved Oil Recovery Symposium, Society of Petroleum Engineers, Tulsa, Oklahoma, USA, 2010. doi:10.2118/129766-MS.

[58] M.A. Buijse, R.M. Prelicz, J.R. Barnes, C. Cosmo, Application of Internal Olefin Sulfonates and Other Surfactants to EOR. Part 2: The Design and Execution of an ASP Field Test, in: SPE Improved Oil Recovery Symposium, Society of Petroleum Engineers, Tulsa, Oklahoma, USA, 2010. doi:10.2118/129769-MS.

[59] J.R. Barnes, K. Groen, A. On, S.T. Dubey, C. Reznik, M.A. Buijse, A.G. Shepherd, Controlled Hydrophobe Branching To Match Surfactant To Crude Composition For Chemical EOR, in: SPE Improved Oil Recovery Symposium, Society of Petroleum Engineers, Tulsa, Oklahoma, USA, 2012. doi:10.2118/154084-MS.

[60] M.A. Buijse, K. Tandon, S. Jain, J.-W. Handgraaf, J. Fraaije, Surfactant Optimization for EOR using Advanced Chemical Computational Methods, in: SPE Improved Oil Recovery Symposium, Society of Petroleum Engineers, Tulsa, Oklahoma, USA, 2012. doi:10.2118/154212-MS.

[61] S. Solairaj, C. Britton, J. Lu, D.H. Kim, U. Weerasooriya, G.A. Pope, New Correlation to Predict the Optimum Surfactant Structure for EOR, in: SPE Improved Oil Recovery Symposium, Society of Petroleum Engineers, Tulsa, Oklahoma, USA, 2012. doi:10.2118/154262-MS.

[62] J.G.E.M. Fraaije, K. Tandon, S. Jain, J.-W. Handgraaf, M. Buijse, Method of Moments for Computational Microemulsion Analysis and Prediction in Tertiary Oil Recovery, Langmuir. 29 (2013) 2136-2151. doi:10.1021/la304505u.

[63] M.A. Buijse, K. Tandon, S. Jain, A. Jain, J.-W. Handgraaf, J.G.E.M. Fraaije, Accelerated Surfactant Selection for EOR Using Computational Methods, in: SPE Enhanced Oil Recovery Conference, Society of Petroleum Engineers, Kuala Lumpur, Malaysia, 2013. doi:10.2118/165268-MS.

[64] S. Ghosh, R.T. Johns, Dimensionless Equation of State to Predict Microemulsion Phase Behavior, Langmuir. 32 (2016) 8969-8979. doi:10.1021/acs.langmuir.6b02666.

[65] S. Ghosh, R.T. Johns, An Equation-of-State Model To Predict Surfactant/Oil/Brine-Phase Behavior, SPE Journal. 21 (2016) 1106-1125. doi:10.2118/170927-PA. 


\title{
Tumor immunosurveillance and immunotherapies: a fresh look from intravital imaging
}

\author{
Morgane Boulch ${ }^{1,2}$, Capucine L. Grandjean ${ }^{1}$, Marine Cazaux ${ }^{1,3}$ \\ and Philippe Bousso ${ }^{1}$
}

Keywords: Tumor immunity, immunosurveillance, immunotherapy, intravital imaging, twophoton microscopy

${ }^{1}$ Dynamics of Immune Responses Unit, Equipe Labellisée Ligue Contre le Cancer, Institut Pasteur, INSERM U1223, 75015 Paris, France.

${ }^{2}$ Master de Biologie, École Normale Supérieure de Lyon, Université Claude Bernard Lyon I, Université de Lyon, 69342 Lyon Cedex 07, France.

${ }^{3}$ University Paris Diderot, Sorbonne Paris Cité, Cellule Pasteur, rue du Dr Roux, 75015 Paris, France.

Correspondence to: philippe.bousso@pasteur.fr 
Understanding complex interactions between the immune system and the tumor microenvironment is an essential step towards the rational development and optimization of immunotherapies. Several experimental approaches are available to tackle this complexity but most are not designed to address the dynamic features of immune reactions including cell migration, cellular interactions and transient signaling events. By providing a unique means to access these precious parameters, intravital imaging offers a fresh look at intratumoral immune responses at the single-cell level. Here, we discuss how in vivo imaging sheds light on fundamental aspects of tumor immunity and helps elucidate modes of action of immunotherapies. We conclude by discussing future developments that may consolidate the unique contribution of intravital imaging for our understanding of tumor immunity.

\section{Decoding mechanisms of tumor immunity}

Recent years have witnessed multiple successes for tumor immunotherapies. Despite these breakthroughs, we are far from fully understanding how the immune system acts within the complexity of the tumor microenvironment (see Glossary) and how to best harness immune cells to eradicate distinct types of tumors. To date, most of the available immunotherapies are only effective in a fraction of patients and in a subset of cancers. A full mechanistic understanding is therefore essential for increasing the efficacy of these treatments, for developing new strategies or for combining them together. Multiple approaches are available to conduct these mechanistic studies. In preclinical models, the manipulation of immune cell subsets (e.g. knock-out models or antibody-based depletion), or the genetic manipulation of tumor cells are routinely used. From human samples, high dimensional flow cytometry or single-cell RNA sequencing are powerful technologies used to establish important correlations and suggest putative mechanisms that might be further explored. These types of 
approaches have provided important insights into the differential modes of action of blocking $\mathrm{T}$ cell co-receptors relevant to immunotherapies, such as via anti-CTLA-4 (cytotoxic T lymphocyte-associated protein 4) or anti-PD-1 (programmed cell death 1) [1]. Most of these strategies however have not directly addressed the most dynamic aspects of immune reactions, such as intratumoral cell migration, the establishment of cell-cell interactions and/or any associated signaling events. Understanding how these dynamic events are modulated by immunotherapies is likely to help unlock some of the secrets behind their modes of action in vivo.

Intravital imaging with single-cell resolution is a technique of choice to address many of these questions in vivo and, in recent years, has helped identify a number of previously unappreciated mechanisms operating in the tumor microenvironment. Here, we provide an overview of models and tools currently available for in vivo imaging, and review how in vivo imaging can shed light on fundamental aspects of tumor immunosurveillance and immunosuppression. We also address how dynamic imaging may help elucidate modes of action of immunotherapies, discussing the development of future technical tools that might reinforce applying intravital imaging to preclinical models of cancer.

\section{Using intravital imaging to assess tumor immunity}

Using optical microscopy at the beginning of the 20th century, pioneering experiments by Elie Metchnikoff demonstrated that immune reactions occurred in transparent organisms, such as Daphnia magna and starfish larvae [2]. As described elsewhere, progress in imaging technology and biological tools have reinvigorated the use of in vivo imaging in the last few decades $[3,4]$. To date, spinning-disk confocal microscopy, laser scanning confocal microscopy, and two-photon microscopy are the three main high-resolution methods for intravital imaging. Each has its own benefits and drawbacks and should be chosen depending 
on the biological constraints. Briefly, spinning-disk confocal imaging is preferred for its rapid image acquisition while conventional laser scanning confocal microscopy can generate images of higher resolution. Finally, two-photon microscopy is most often used for deep tissue imaging as it relies on fluorophore excitation by low-energy infrared light.

Intravital imaging in mouse models has provided significant insights into basic immune mechanisms of lymphocyte activation or effector immune responses in a variety of contexts. Applied to preclinical models of cancer with relevant fluorescent labeling, in vivo imaging approaches can therefore offer access to numerous dynamic processes in the tumor microenvironment, with the potential to reveal new mechanisms of immune cell activity during tumor development, or during the course of tumor immunotherapies. For instance, by offering crucial information on cellular interactions, cell motility and cell signaling, numerous intravital imaging studies have proven useful in identifying cellular partners as well as determining whether cells are engaged in antigen-specific interactions (Figure 1, Key Figure). The typical workflow for assessing host-tumor interactions in animal models using intravital imaging is described in Box 1. Of note, a number of in vivo imaging studies have examined the role of the tumor vasculature in influencing indirectly immune responses; we refer the reader to excellent published reviews on that topic $[5,6]$.

\section{Models and tools for intravital imaging of tumor immunity}

A large and constantly expanding toolbox is available for intravital imaging of antitumor immune responses. Both human and mouse models have been developed to microscopically explore antitumor immunity. Tumors derived from patients can be transplanted, orthotopically or ectopically, into immunodeficient mice (such as NSG (NOD scid gamma) mice) directly, patient-derived xenograft (PDX) models, or following in vitro culturing (cell line-derived xenograft (CDX) models). In addition, transgenic mice engineered to develop 
spontaneous cancers (such as models of breast cancer in MMTV-PyMT mice [7] and B-cell lymphoma in $\mathbf{E} \boldsymbol{\mu}$-myc mice [8,9]) are suitable to visualize immune responses during the course of tumor development. Strategies to fluorescently label spontaneously developing tumors have been incorporated in some models to facilitate imaging approaches. Alternatively, these spontaneous tumors can be isolated, fluorescently labeled and reinjected into secondary recipients. Finally, syngeneic mouse tumor cell lines expressing geneticallyencoded fluorescent proteins or reporters have been used extensively for imaging purposes.

In tumor-bearing mice, intravital imaging has been performed in numerous anatomical sites, including the skin, lungs, mammary fatpads, digestive tract, liver, kidney, lymph nodes, bone marrow and brain. Moreover, window chambers offer an opportunity to image one particular site at multiple time points, thus giving insights into the progression of any given immune reaction in the same organism [10-15]. Alternatively, techniques using human tumor slices (e.g. from lung, ovarian tumor biopsies) obtained from patients can provide valuable information regarding immune cell behavior in the complex tumor microenvironment. Table 1 summarizes various tumor models, anatomical sites and immune cells that have been, or are currently the focus of intravital imaging studies.

While a wide range of fluorescent proteins is available to label immune and tumors cells, their combination with reporters that measure functional parameters provides an additional layer of information. Examples of genetically-encoded functional reporters used to dissect host-tumor interactions are shown in Figure 2. For example, tumor cells can express probes to visualize apoptosis [16,17] and proliferation [18] in the tumor microenvironment. Tumor multicolor barcoding provides a means to study tumor clonal heterogeneity, and can give insights into tumor spatial organization [19,20]. In addition, immune cell activity can be tracked using gene reporters for signal transduction --including calcium signaling [17], and nuclear factor of activated T cells (NFAT) nuclear translocation [21] -- or for cytokine production -- using for 
instance, interferon gamma (IFN- $\gamma$ ) or interleukin 12 (IL-12) reporters [11]. Of note, additional fluorescent reporters, such as oxygen probes and redox ratios, have been used in mice to image cancer development or responses to chemotherapy and could be potentially applied for the study of tumor immunity [5,22]. The continuous development of new genetically-encoded fluorescent probes to track conditions such as metabolic activity, cell phenotype and functional states may help foster new concepts in tumor immunity.

\section{Mechanisms of tumor immunosurveillance and immunosuppression}

\section{Tracking tumor infiltration.}

Tumor immunosurveillance requires migration and infiltration of effector cells into the tumor, and intravital imaging studies have helped unveil mechanisms where tumor encounters are either promoted or limited. For example, cytotoxic $\mathrm{T}$ lymphocytes (CTL) have been visualized: migrating, stably interacting with, and directly killing antigen-expressing subcutaneous thymoma cells in mice in vivo $[16,23,24]$. These studies have highlighted the role of cognate antigen expression on tumor cells in promoting CTL migration and intratumoral infiltration. Additionally, interactions between extracellular matrix proteins and CD44 expressed on CTL have been reported to be key determinants of interstitial migration in various CD44-deficient mouse models of E.G7-OVA-ECFP subcutaneous tumors [25]. A patrolling $\mathrm{T}$ cell behavior can be key to maintaining cancer-immune equilibria, as evidenced, for instance, in a melanoma mouse model of resident memory $\mathrm{CD}^{+} \mathrm{T}$ cells in the epidermis [26]. Of note, distinct effector immune cells may exhibit different immunosurveillance strategies; for example, NK cells tend to form less stable conjugates with tumor cells than CTLs, a feature that may favor their intratumoral dissemination in mouse EL4 Rae-1 $\beta$ tumor models [27]. 
However, several mechanisms have also been shown to limit intratumoral CTL infiltration. Specifically, imaging studies of human lung and ovarian cancer slices reported that stromal collagen fibers could contribute to limiting CTL access to tumor cells [28-30]. CTL retention can also be promoted by macrophages [31] and dendritic cells (DCs) [32] in the form of unproductive stable interactions, as visualized in human tumor slices and murine models. Finally, CTL sequestration by apoptotic tumor cells may also limit intratumoral dissemination and reduce killing rates, as evidenced from tumor mouse models [16]. Collectively, these studies highlight the need to delineate new strategies that can promote optimal and effective $\mathrm{T}$ cell-tumor cell encounters to improve antitumor responses.

\section{Identifying cellular partners.}

Visualizing dynamic cellular interactions can reveal putative cooperation and crosstalk between distinct immune cell types during antitumor immunity. For example, using a premetastatic B16.F10 melanoma mouse model, a study reported that melanoma-derived antigens could be captured by subcapsular macrophages in the tumor-draining lymph nodes and then deposited on follicular dendritic cells, thus promoting a humoral immune response [33]. At the tumor margin, in a fluorescent mouse model of spontaneous breast cancer (based on MMTV-PyMT), rare activating $\mathrm{CD}_{103^{+}} \mathrm{DCs}$ were shown to compete for CTL interactions with tumor-associated macrophages and favor tumor elimination [34,35]. Moreover, previously unsuspected stable NK-DC conjugates in the mouse melanoma microenvironment have been deemed decisive in achieving effective antitumor responses, as evidenced from mouse B16F10 melanoma tumor models [36].

Delineating the role of immunosuppressive cells. 
Intravital imaging can also shed light on immunosuppressive mechanisms operating in the tumor microenvironment. For instance, using multi-photon microscopy in a mouse model of adoptive transfer of HA-transduced CT44 colon carcinoma cells, regulatory T cells (Tregs) were shown to limit the killing ability of CTLs by reducing granule exocytosis, rather than by altering their capacity to form conjugates with target cells [37]. As an additional suppressive mechanism, intravital imaging has suggested that FoxP3 ${ }^{+}$Tregs can kill DCs in tumordraining lymph nodes (in a mouse model of OVA-expressing MCA101 fibrosarcoma tumors), and limit the onset of CTL responses [38]. At the tumor site, Tregs can establish interactions with antigen-presenting cells (APCs), decreasing the surface expression of costimulatory molecules such as CD80 and CD86 on APCs and subsequently promoting CTL dysfunction in subcutaneous CT26HA mouse tumors [39]. Similarly, in an orthotopic pancreatic ductal adenocarcinoma mouse model (using GFP-Kras ${ }^{\mathrm{G} 12 \mathrm{D}}$-pancreatic ductal epithelial cells), Treg depletion promoted the accumulation of intratumoral DCs and their expression of costimulatory molecules (e.g. CD40 and CD86), which subsequently favored prolonged contacts between CTLs and DCs [40]. Moreover, in another study, Tregs were reported to form a ring around B16 melanoma mouse tumors which could be disrupted following cyclophosphamide administration (a chemotherapeutic agent used in lymphodepleting, conditioning regimens for adoptive cell transfer protocols), thus favoring the intra-tumoral infiltration of adoptively transferred CTLs [41]. Finally, the process of immunosuppressive cell recruitment can also be studied with in vivo imaging approaches. In this context, the transmigration of immunosuppressive $\mathrm{Ly} 6 \mathrm{C}^{\mathrm{lo}}$ monocytes in mouse colorectal tumors has been reported to rely on the CX3CL1/CX3CR1 axis (using $C x 3 \mathrm{crl}^{-/-}$mice) [14]. Altogether, these imaging studies suggest potential target avenues for blocking the recruitment and activities of immunosuppressive cells in the tumor microenvironment. 
Uncovering spatial heterogeneity in the tumor microenvironment.

An important outstanding question is whether immunosurveillance can occur uniformly across different tumor areas, or whether it varies due to local constraints, therefore possibly creating niches for tumor escape. Tumor-antigen specific $\mathrm{CD} 8^{+} \mathrm{T}$ cells have been shown to traffic differently in zones containing distinct lymphoma subclones in the bone marrow, as revealed by multicolor tumor barcoding and intravital imaging in a murine MYC-driven B cell lymphoma [20]. As an additional factor promoting spatial heterogeneity in the immune infiltrate, intratumoral hypoxia in mouse models of B cell acute lymphocytic leukemia (BALL) have been inversely correlated with tumor-infiltrating $\mathrm{T}$ cell motility, especially within the core of the solid tumor compared to the tumor margin [42]. Similarly, tumor-associated macrophages tracked with an Arginase-1 reporter can also exhibit distinct behaviors and morphology, depending on whether they are located at the center or at the periphery of solid tumors, as described in the syngeneic MC38 tumor mouse model [43]. Collectively, these studies highlight the importance of tumor microanatomy in the regulation of immune cell activity.

\section{Visualizing tumor metastasis.}

Intravital imaging can also provide mechanistic insight into tumor cell intravasation and metastasis. These processes have been visualized for example, using the MMTV-PyMT mouse model of breast cancer, revealing a role for macrophages in inducing loss of vascular junctions [44]. Another study imaged how pioneer melanoma cells dynamically generated tumor microparticles in the lung vasculature when injected intravenously in mice [13]. Specifically, ingestion of these tumor microparticles by monocytes and $\mathrm{CD}_{103^{+}}$DCs recruited in the lungs elicited pro- and anti-metastatic effects, respectively [13]. Finally although entirely depending on context -- neutrophils have also been reported to contribute to 
tumor metastasis through the generation of neutrophil extracellular traps (NETs), processes which were observed to surround metastatic cells in murine lungs in the mouse model of 4T1 breast cancer [45].

As illustrated in this section, the use of intravital imaging has opened new opportunities to revealing dynamic tumor-immune cell interactions at various stages of tumor development, to pinpoint novel cellular partnerships, and to identify new putative targets that might be assessed to ideally boost immunosurveillance or circumvent immunosuppression.

\section{Toward a single-cell understanding of the modes of action of tumor immunotherapies}

With intense efforts to develop new and efficient antitumor immunotherapies, more than ever, it is essential to fully understand how these therapies precisely work in vivo. Thus, the use of intravital imaging can be decisive in confirming, clarifying or challenging other data, or perhaps preconceived ideas (obtained most often using in vitro experiments), regarding the presumed modes of action of specific immunotherapeutic drugs.

\section{Tumor-targeting antibodies.}

Directly targeting tumors via monoclonal antibodies (mAb) can be an effective strategy to reduce tumor burden, as illustrated by the clinical use of anti-CD20, anti-EGFR (epidermal growth factor receptor) or anti-HER2 (human epidermal growth factor receptor 2) mAb for treating certain lymphomas, colorectal, and breast cancers, respectively [46]. Multiple modes of action have been proposed for mAb, including Fc-independent effects, as well as Fcdependent mechanisms, such as complement-dependent cytotoxicity (CDC), antibodydependent cellular cytotoxicity (ADCC) or phagocytosis (ADP) [47]. Yet, the respective contribution of each of these mechanisms in vivo is not well characterized. It is also unclear 
whether different mechanisms operate at distinct anatomical sites. Intravital imaging has proven to be an invaluable tool to directly address these key questions. For example, two independent studies provided evidence that ADP by Kupffer cells (KC) in the murine liver was a major mechanism for mAb-mediated tumor cell depletion $[48,49]$. Specifically, KC were visualized and shown to engulf circulating normal and malignant B cells within minutes following anti-CD20 mAb administration in a mouse model of spontaneous lymphoma [48]. Similarly, KC eliminated circulating B16 melanoma tumor cells and C26 colon carcinoma cells upon anti-TRP1 mAb therapy, thus preventing liver metastasis in mice [49]. Notably, glycoengineering of the anti-CD20mAb has lowered the threshold for $\mathrm{KC}$-mediated depletion during mAb therapy in mouse liver transplant models[50]. While these studies have largely focused on circulating tumors, the modes of action of tumor-targeting mAb in solid tumors or in tumors established within lymphoid tissues remain to be identified. To date, ADCC by NK cells has rarely been visualized in mouse models of tumor-targeting mAb treatments, despite being largely reported in in vitro studies. For instance, In one study, using subcutaneously injected EL4 thymoma cells in mice, Fc-mediated recognition of tumor-bound mAb by NK cells was not sufficient to induce target killing, but was required to stabilize interactions with target cells, thus facilitating cell killing through the NKG2D activating receptor [51].

From another angle, bispecific antibodies have been engineered to promote contacts between tumors and effector cells. A recent study used a bispecific Ab targeting CD3 and the carcinoembryonic (CEA) tumor antigen in a colon carcinoma xenograft mouse model, confirmed via in vivo fluorescence imaging, that treatment with the bispecific Ab promoted $\mathrm{T}$ cell interactions with tumors, thus resulting in greater cytotoxic activity at the tumor site relative to controls [12].

Immune checkpoint blockade. 
Immune checkpoint blockers (ICB), including mAb that target CTLA-4, PD-1 or PD-L1 (programmed death ligand 1), have shown great promise for the treatment of some cancers [52], yet a complete understanding of their in vivo modes of action is lacking.

In vivo imaging has revealed that $\mathrm{ICB}$ can have a strong impact on intratumoral $\mathrm{T}$ cell dynamics. Specifically, treatment with anti-CTLA-4 mAb appeared to increase overall B16 melanoma-or CFP-4T1 tumor-specific $\mathrm{CD}^{+} \mathrm{T}$ cell motility in mouse tumors, although the underlying mechanisms are unclear [53,54]. A study of allo-hematopoietic stem cell transplantation (HSCT) in a mouse model of $\mathrm{H}-\mathrm{Y}$ minor histocompatibility mismatch, reported that PD-1 blockade could restore CTL conjugation to target tumor cells and their subsequent killing activity in lymph nodes, in the context of graft versus leukemia effects [55]. Indeed, anti-PD-1 activity might also benefit from releasing $\mathrm{CD} 8^{+} \mathrm{T}$ cells engaged in unproductive interactions with macrophages, as visulaized in a spontaneous murine model of breast cancer [31].

Imaging studies have also been key in uncovering unexpected aspects of anti-PD-1 therapy. For example, visualizing the fate of labeled anti-PD-1 mAb in mice bearing MC38 colon carcinomas revealed that after binding to $\mathrm{T}$ cells, these reagents were rapidly captured by neighboring macrophages in an Fc receptor-dependent manner [56]. Blocking this capture process increased anti-PD-1 activity by prolonging mAb binding time on $\mathrm{T}$ cells [56]. Moreover, intratumoral imaging using reporters for IFN- $\gamma$ and IL-12 cytokines have contributed to identifying key cellular crosstalk events between DCs and CTLs mediating anti-PD-1 therapeutic effects in a mouse model of MC38 tumors; in this model, IFN- $\gamma$ released by anti-PD-1-sensitized T cells was essential to inducing IL-12-production by DCs, thereby increasing CTL antitumor activity [11]. Presumably, anti-PD-1 treatment might not only act to reduce tumor burden but might also finely tune its subclonal heterogeneity [20], a phenomenon that should be considered when designing combination therapies. 


\section{Targeting macrophages.}

Targeting tumor-associated macrophages (TAMs) may offer ways to release $\mathrm{T}$ cells and promote their dissemination in the tumor as mentioned previously. In addition, depleting macrophages using anti-CSF1 (colony stimulating factor 1) mAb has been shown to restore tumor blood vessel patterning and function as visualized by longitudinal multiphoton imaging in a mouse glioma model (CT2A and GL261) [15]. Additionally, intravital confocal imaging has been used in a mouse model of MMTV-PyMT breast cancer to better characterize the impact of depleting the myeloid cell compartment via anti-CFS1R mAb, leading to delayed tumor growth; of note depleted cells shared markers of TAMs and DCs [57]. Finally, targeting the protease-dependent mesenchymal mode of migration of TAMs in a subcutaneous fibrosarcoma mouse model has been shown to limit the recruitment of TAMs, which subsequently reduced tumor growth [10].

\section{Cell therapy.}

Infusing expanded tumor-infiltrating lymphocytes (TILs) or genetically engineered T cells that express a tumor-specific TCR or a chimeric antigen receptor (CAR) can represent an effective strategy to control tumor burden [58]. Among the important outstanding questions is how efficiently transferred effectors infiltrate the tumor and at which rate they kill tumor targets. Strategies to visualize tumor killing in real-time can provide insights into these important parameters. In a mouse model of solid tumor using EL4 thymoma, adoptively transferred CTLs were found to kill tumor cells at a relatively low rate (1 killing event per CTL every $6 \mathrm{~h}$ on average) and their accumulation at high density was essential to inducing tumor regression [16]. Combining therapies might boost killing activity as illustrated by the use of an agonistic anti-CD137 ( $\mathrm{T}$ cell co-receptor) mAb which promoted the cytotoxic 
activity of transferred CTLs in a B16F10-derived OVA-expressing mouse melanoma model [59]. Notably, CTL activity can vary extensively depending on the anatomical site. As prviosuly discussed, in a mouse model of graft versus leukemia effect, CTL recognition was specifically silenced in lymph nodes due to widespread PD-L1 upregulation, as visualized by two-photon imaging [55]. CTL activity can also be modulated over time, as evidenced from imaging experiments using the PyMT-ChOVA tumor mouse model, showing that the ability of CTL to stably engage tumor targets decreased with their residence time in the tumor microenvironment, relative to controls [60].

In a mouse model of E $\mu$-myc spontaneous Burkitt-like B cell lymphoma, real-time imaging of CAR-T cell killing and signaling using Förster resonance energy transfer (FRET)-based probes for apoptosis, and calcium signaling, revealed extensive heterogeneity in CAR-T cell activity [17]. Nevertheless, a subset of CAR-T cells could engage, kill and detach from tumor targets in a short period of time $(25 \mathrm{~min})$ and these events were sufficient to eliminate the bulk of tumor cells [17]. Imaging may indeed help to validate strategies to overcome tumor escape from CAR-T cell therapy; in one study using a mouse model of B-ALL (antigen-loss CD19-negative relapse xenograft), the use of $\mathrm{T}$ cells expressing two distinct CARs directed against the CD19 and CD123 molecules showed that the combination treatment prevented antigen-loss relapse, and was linked with the ability of these CAR-T cells to interact with CD19-negative leukemia cells [61]. The sum of such studies suggests that intravital imaging can improve our mechanistic understanding of these types of treatments, as well as provide potential clues about which approaches might lead to improving cell therapies in vivo.

\section{Concluding Remarks}

By providing dynamic information at the single-cell level in the tumor microenvironment, intravital imaging represents a powerful approach to identifying fundamental mechanisms of 
tumor immunosurveillance and immunosuppression. In addition, this approach is refining, when not redefining, our understanding of how immunotherapies might actually be occurring in vivo (Figure 3). This knowledge is essential to identify ways to improve, or combine immunotherapies effectively. For this reason, one should consider including intravital imaging experiments as an essential step in preclinical designs of putative novel immunotherapies. Moreover, intravital imaging can be combined with other techniques. For instance, dynamic in situ cytometry (DISC) relies on cell surface labeling to link phenotypic markers and motility parameters [62]. Photoactivation of fluorescent proteins can be used to pinpoint some of the cells imaged and subsequently analyze these by flow cytometry [63], or single-cell RNA sequencing (Niche-Seq) [64]. Imaging can also be coupled to techniques that mark cell-cell interactions such as the LIPSTIC (Labeling Immune Partnerships by SorTagging Intercellular Contacts) approach [65]. Indeed, many new questions and challenges lie ahead (OUTSTANDING QUESTIONS); new mouse models of cancer relevant to human diseases, emerging immunotherapies, as well as novel functional reporters and optogenetic strategies can be used to manipulate immune cells during imaging (Box 2); these approaches can further establish intravital imaging as a unique and essential tool enabling a deeper understanding of immune cell activities in the tumor microenvironment, and informing putative immunotherapeutic approaches to treating malignancies. 


\section{Box 1. Technical workflow for intravital imaging}

A typical intravital imaging experiment proceeds through the following steps:

\section{Choosing the relevant model to image}

- Select a genetically-engineered spontaneous or transplantable fluorescent mouse model of cancer

- Use fluorescent reporter recipients to visualize immune cells of interest and/or adoptively transfer fluorescently labeled immune cells

\section{Reaching the site of imaging}

- Insert window chamber for longitudinal imaging

- Surgically expose the site of interest for immediate imaging

\section{Image acquisition and data collection}

- Maintain optimal and physiological conditions for animal welfare and imaging quality: anesthesia, analgesia, temperature, oxygen, etc.

- Choose the correct mirrors and filters to visualize fluorescent cells

- Choose the appropriate laser wavelength for the excitation of the distinct fluorescent proteins and dyes

- Determine acquisition parameters (laser power, 3D volume, scanning rate and time intervals)

- Define length of the recording

\section{Data extraction and analysis}

- Choose a relevant software for time-lapse movie analysis

- Determine the parameters to be quantified in the regions of interest (speed, confinement, shape, signal intensity, contacts, etc.)

- Proceed to automated (e.g. cell tracking) or manual parameter quantification

- Graph the extracted data

- Assemble the time-lapse movie as 2D projection of the 3D volume (legends, time display, scale bar) 


\section{Box 2. Combining intravital imaging and optogenetics to manipulate individual immune cells}

The use of light sensitive-proteins has allowed the engineering of multiple geneticallyencoded systems to manipulate cellular function with exquisite spatiotemporal control (referred to as actuators) [66,67]. These technologies, termed optogenetics, have been used extensively in neuroscience but have only emerged recently as a new tool for immunologists. For example, optogenetic tools have already been used to manipulate trafficking of immune cells in vivo, by using a system in which the chemokine CXCR4 signal is triggered by light exposure in mice [68]. Calcium actuators that trigger aggregation of stromal interaction molecule 1 (STIM1) can elicit DC activation or augment $\mathrm{CD}^{+} \mathrm{T}$ cell cytotoxicity in vitro, and in subcutaneous B16 mouse melanoma models [69,70]. Chemokine secretion [71] or TCR signaling $[72,73]$ can also be manipulated with light. To date, most optogenetic approaches with immune cells have been conducted in vitro or in vivo by bulk photoactivation of the whole tumor, but combined with intravital imaging, optogenetic actuators might also potentially allow the manipulation of single immune cells as we observe them. This may offer a unique ability to understand the functional contribution of specific cells and/or the consequence of a given cellular function in the tumor microenvironment. Among the challenges facing the use of single-cell optogenetics in tumors is the ability to design actuators with low background activity and high response rates, to introduce actuators in primary immune cells, and to photoactivate cells located deeply inside tumors. Yet, controlling single immune cells in tumors and assessing the functional consequences of such manipulations may represent an important milestone in the field of in intravital imaging. 


\section{Glossary}

Actuators: Genetically-encoded tools for light-activated control of proteins regulating cellular functions.

ADCC: cytotoxic immune response often elicited by NK cells following recognition of Fc receptors on antibody-bound tumor cells; this results in delivery of their cytotoxic content unto the target cell and its subsequent death.

Adoptive cell transfer: therapy based on the isolation and the infusion of immune cells into the same or another individual/host.

ADP: mechanism by which macrophages can recognize, via Fc receptors, antibody bound to tumor cells, resulting in cell engulfment and destruction.

B cell lymphoma: B cell-derived tumors developing in lymphoid organs.

Bispecific antibodies: Synthetic antibodies that can simultaneously bind two distinct antigens.

CAR-T: $T$ cells genetically engineered to express synthetic receptors composed of intracellular signaling domains fused to an antibody-derived recognition domain specific for surface target antigens.

CDC: lysis mechanism triggered by the recruitment of molecules of the complement pathway upon antibody binding to its target cells.

DISC: technique combining the advantages of intravital imaging and flow cytometry analysis to link cell behavior and phenotype in vivo.

Ectopic transplantation: occurs in a different anatomical site than the original location in the donor. 
E $\mu$-myc mice: Genetically modified mice that express the oncogene c-myc driven by the immunoglobulin heavy chain enhancer ; they develop spontaneous aggressive B-cell lymphoma.

FRET: energy transfer between a pair of adjacent fluorophores; used to monitor proximity between protein domains, conformational changes or protein cleavage.

Graft versus leukemia effect: immune response against host leukemic cells mediated by transplanted donor immune cells.

ICB: strategy aiming to increase immune responses via blockade of immunoreceptors, thus inhibiting the activity of immune effector cells.

Kupffer cells: Resident macrophages found in the liver.

LIPSTIC: technique that enables the identification of receptor-ligand interactions between cells by using intercellular enzymatic labeling. When a ligand and its receptor interact, the enzyme mediates the transfer of a substrate unto the tagged receptor.

MMTV-PyMT model: transgenic mouse model of breast cancer. The mammary tumor virus long terminal repeat (MMTV-LTR) drives the expression of mammary gland specific polyomavirus middle $\mathrm{T}$ antigen (PyMT), resulting in a rapid development of highly metastatic tumors.

Multicolor barcoding: series of approaches to randomly label individual tumor cells with one of multiple fluorescent proteins, and trace subclonal progenies. Barcoding can be performed ex vivo by transducing tumor cells prior to transfer, or directly in vivo using Cre recombinase-based random genetic recombination in transgenic mouse models.

NETs: DNA meshes associated to cytotoxic enzymes; released in the extracellular space by neutrophils; can trap, neutralize and kill pathogens.

Niche-Seq: technique that uses photoactivatable fluorescent proteins to sort and analyze gene expression of cells located in selected areas of a specific tissue. 
NKG2D: activating receptor expressed by NK and T cells.

Orthotopic transplantation: occurs in the same anatomical site where cells or a tissue were originally extracted from the donor.

STIM1: transmembrane protein, mainly localized in the endoplasmic reticulum, involved in the control of calcium entry within the intracellular space.

Syngeneic: Sharing the same genetic background.

TILs: Lymphocytes infiltrating the tumor microenvironment.

Transmigration: cells cross the endothelium vessel wall.

Tregs: subset of $\mathrm{T}$ cells specialized in the suppression of $\mathrm{T}$ cell responses.

Tumor microenvironment: surrounds and feeds tumor cells. This includes blood vessels, immune cells, fibroblasts, extracellular matrix and signaling molecules.

Tumor microparticles: Microscale blebs that shed from a tumor cell.

Two-photon microscopy: fluorescence imaging technique that uses two photons of lowenergy infrared light to excite fluorophores. This greatly improves imaging depth compared to confocal microscopy and reduces phototoxic effects associated with visible light.

Window chamber: Glass-covered structure surgically implanted into the recipient (e.g. mouse) to enable repeated imaging of a tissue by intravital microscopy.

Xenograft: tissue graft originating from a different species than the recipient. 


\section{Acknowledgments}

We thank Mikael Pittet, Thorsten Mempel, Thomas Gebhardt for kindly providing images.

The work was supported by Institut Pasteur, Inserm and an Advanced grant (ENLIGHTEN) from the European Research Council (P.B). 


\section{References}

1 Wei, S.C. et al. (2017) Distinct Cellular Mechanisms Underlie Anti-CTLA-4 and Anti-PD-1 Checkpoint Blockade. Cell 170, 1120-1133.e17

2 Gordon, S. (2008) Elie Metchnikoff: Father of natural immunity. European Journal of Immunology 38, 3257-3264

3 Ritsma, L. et al. (2012) Intravital imaging of cell signaling in mice. IntraVital 1, 2-10

4 Secklehner, J. et al. (2017) Intravital microscopy in historic and contemporary immunology. Immunol Cell Biol 95, 506-513

5 Ellenbroek, S.I.J. and Rheenen, J. van (2014) Imaging hallmarks of cancer in living mice. Nature Reviews Cancer 14, 406-418

6 Fukumura, D. et al. (2010) Tumor Microvasculature and Microenvironment: Novel Insights Through Intravital Imaging in Pre-Clinical Models. Microcirculation 17, 206-225

7 Guy, C.T. et al. (1992) Induction of mammary tumors by expression of polyomavirus middle T oncogene: a transgenic mouse model for metastatic disease. Molecular and Cellular Biology 12, 954-961

8 Adams, J.M. et al. (1985) The c- myc oncogene driven by immunoglobulin enhancers induces lymphoid malignancy in transgenic mice. Nature 318, 533

9 Harris, A.W. et al. (1988) The E mu-myc transgenic mouse. A model for highincidence spontaneous lymphoma and leukemia of early B cells. Journal of Experimental Medicine 167, 353-371

10 Gui, P. et al. (2018) The Protease-Dependent Mesenchymal Migration of TumorAssociated Macrophages as a Target in Cancer Immunotherapy. Cancer Immunol Res 6, $1337-1351$

11 Garris, C.S. et al. (2018) Successful Anti-PD-1 Cancer Immunotherapy Requires T 
Cell-Dendritic Cell Crosstalk Involving the Cytokines IFN- $\gamma$ and IL-12. Immunity 49, 11481161.e7

12 Lehmann, S. et al. (2016) In Vivo Fluorescence Imaging of the Activity of CEA TCB, a Novel T-Cell Bispecific Antibody, Reveals Highly Specific Tumor Targeting and Fast Induction of T-Cell-Mediated Tumor Killing. Clin Cancer Res 22, 4417-4427

13 Headley, M.B. et al. (2016) Visualization of immediate immune responses to pioneer metastatic cells in the lung. Nature 531, 513-517

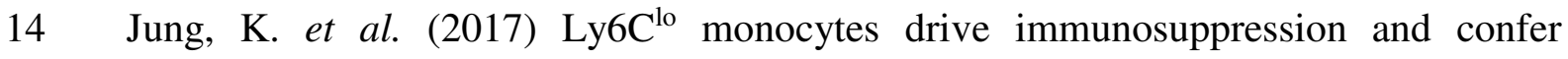
resistance to anti-VEGFR2 cancer therapy. J Clin Invest 127, 3039-3051

15 Mathivet, T. et al. (2017) Dynamic stroma reorganization drives blood vessel dysmorphia during glioma growth. EMBO Molecular Medicine 9, 1629-1645

16 Breart, B. et al. (2008) Two-photon imaging of intratumoral $\mathrm{CD}^{+} \mathrm{T}$ cell cytotoxic activity during adoptive T cell therapy in mice. J Clin Invest 118, 1390-1397

17 Cazaux, M. et al. (2019) Single-cell imaging of CAR T cell activity in vivo reveals extensive functional and anatomical heterogeneity. Journal of Experimental Medicine DOI: 10.1084/jem.20182375

18 Yano, S. and Hoffman, R.M. (2018) Real-Time Determination of the Cell-Cycle Position of Individual Cells within Live Tumors Using FUCCI Cell-Cycle Imaging. Cells 7, 168

19 Zomer, A. et al. (2013) Brief Report: Intravital Imaging of Cancer Stem Cell Plasticity in Mammary Tumors. Stem Cells 31, 602-606

20 Milo, I. et al. (2018) The immune system profoundly restricts intratumor genetic heterogeneity. Science Immunology 3, eaat 1435

21 Marangoni, F. et al. (2013) The Transcription Factor NFAT Exhibits Signal Memory during Serial T Cell Interactions with Antigen-Presenting Cells. Immunity 38, 237-249 
22 Conway, J.R.W. et al. (2014) Developments in preclinical cancer imaging: innovating the discovery of therapeutics. Nature Reviews Cancer 14, 314-328

23 Boissonnas, A. et al. (2007) In vivo imaging of cytotoxic T cell infiltration and elimination of a solid tumor. Journal of Experimental Medicine 204, 345-356

24 Mrass, P. et al. (2006) Random migration precedes stable target cell interactions of tumor-infiltrating T cells. Journal of Experimental Medicine 203, 2749-2761

25 Mrass, P. et al. (2008) CD44 Mediates Successful Interstitial Navigation by Killer T Cells and Enables Efficient Antitumor Immunity. Immunity 29, 971-985

26 Park, S.L. et al. (2019) Tissue-resident memory CD8 + T cells promote melanomaimmune equilibrium in skin. Nature 565, 366-371

27 Deguine, J. et al. (2010) Intravital Imaging Reveals Distinct Dynamics for Natural Killer and CD8+ T Cells during Tumor Regression. Immunity 33, 632-644

28 Salmon, H. et al. (2012) Matrix architecture defines the preferential localization and migration of T cells into the stroma of human lung tumors. J Clin Invest 122, 899-910

29 Peranzoni, E. et al. (2017) Ex Vivo Imaging of Resident CD8 T Lymphocytes in Human Lung Tumor Slices Using Confocal Microscopy. JoVE (Journal of Visualized Experiments) DOI: $10.3791 / 55709$

30 Bougherara, H. et al. (2015) Real-Time Imaging of Resident T Cells in Human Lung and Ovarian Carcinomas Reveals How Different Tumor Microenvironments Control T Lymphocyte Migration. Front. Immunol. 6,

31 Peranzoni, E. et al. (2018) Macrophages impede CD8 T cells from reaching tumor cells and limit the efficacy of anti-PD-1 treatment. PNAS 115, E4041-E4050

32 Boissonnas, A. et al. (2013) CD8+ Tumor-Infiltrating T Cells Are Trapped in the Tumor-Dendritic Cell Network. Neoplasia 15, 85-94

33 Moalli, F. et al. (2015) Intravital and Whole-Organ Imaging Reveals Capture of 
Melanoma-Derived Antigen by Lymph Node Subcapsular Macrophages Leading to Widespread Deposition on Follicular Dendritic Cells. Front. Immunol. 6,

34 Engelhardt, J.J. et al. (2012) Marginating Dendritic Cells of the Tumor Microenvironment Cross-Present Tumor Antigens and Stably Engage Tumor-Specific T Cells. Cancer Cell 21, 402-417

35 Broz, M.L. et al. (2014) Dissecting the Tumor Myeloid Compartment Reveals Rare Activating Antigen-Presenting Cells Critical for T Cell Immunity. Cancer Cell 26, 638-652 36 Barry, K.C. et al. (2018) A natural killer-dendritic cell axis defines checkpoint therapy-responsive tumor microenvironments. Nature Medicine 24, 1178

37 Mempel, T.R. et al. (2006) Regulatory T Cells Reversibly Suppress Cytotoxic T Cell Function Independent of Effector Differentiation. Immunity 25, 129-141

38 Boissonnas, A. et al. (2010) Foxp3+ T Cells Induce Perforin-Dependent Dendritic Cell Death in Tumor-Draining Lymph Nodes. Immunity 32, 266-278

39 Bauer, C.A. et al. (2014) Dynamic Treg interactions with intratumoral APCs promote local CTL dysfunction. J Clin Invest 124, 2425-2440

40 Jang, J.-E. et al. (2017) Crosstalk between Regulatory T Cells and Tumor-Associated Dendritic Cells Negates Anti-tumor Immunity in Pancreatic Cancer. Cell Reports 20, 558571

41 Qi, S. et al. (2016) Long-term intravital imaging of the multicolor-coded tumor microenvironment during combination immunotherapy. eLife 5, e14756

42 Rytelewski, M. et al. (2019) Merger of dynamic two-photon and phosphorescence lifetime microscopy reveals dependence of lymphocyte motility on oxygen in solid and hematological tumors. Journal for ImmunoTherapy of Cancer 7, 78

43 Arlauckas, S.P. et al. (2018) Arg1 expression defines immunosuppressive subsets of tumor-associated macrophages. Theranostics $8,5842-5854$ 
44 Harney, A.S. et al. (2015) Real-Time Imaging Reveals Local, Transient Vascular Permeability, and Tumor Cell Intravasation Stimulated by TIE2hi Macrophage-Derived VEGFA. Cancer Discov 5, 932-943

45 Park, J. et al. (2016) Cancer cells induce metastasis-supporting neutrophil extracellular DNA traps. Science Translational Medicine 8, 361ra138-361ra138

46 Reichert, J.M. and Dhimolea, E. (2012) The future of antibodies as cancer drugs. Drug Discovery Today 17, 954-963

47 Weiner, L.M. et al. (2010) Monoclonal antibodies: versatile platforms for cancer immunotherapy. Nature Reviews Immunology 10, 317-327

48 Montalvao, F. et al. (2013) The mechanism of anti-CD20-mediated B cell depletion revealed by intravital imaging. J Clin Invest 123, 5098-5103

49 Gül, N. et al. (2014) Macrophages eliminate circulating tumor cells after monoclonal antibody therapy. J Clin Invest 124, 812-823

50 Grandjean, C.L. et al. (2016) Intravital imaging reveals improved Kupffer cellmediated phagocytosis as a mode of action of glycoengineered anti-CD20 antibodies. Scientific Reports 6, 34382

51 Deguine, J. et al. (2012) Cutting Edge: Tumor-Targeting Antibodies Enhance NKG2D-Mediated NK Cell Cytotoxicity by Stabilizing NK Cell-Tumor Cell Interactions. The Journal of Immunology 189, 5493-5497

52 Seidel, J.A. et al. (2018) Anti-PD-1 and Anti-CTLA-4 Therapies in Cancer: Mechanisms of Action, Efficacy, and Limitations. Front. Oncol. 8,

53 Pentcheva-Hoang, T. et al. (2014) Cytotoxic T Lymphocyte Antigen-4 Blockade Enhances Antitumor Immunity by Stimulating Melanoma-Specific T-cell Motility. Cancer Immunol Res 2, 970-980

54 Ruocco, M.G. et al. (2012) Suppressing T cell motility induced by anti-CTLA-4 
monotherapy improves antitumor effects. J Clin Invest 122, 3718-3730

55 Michonneau, D. et al. (2016) The PD-1 Axis Enforces an Anatomical Segregation of CTL Activity that Creates Tumor Niches after Allogeneic Hematopoietic Stem Cell Transplantation. Immunity 44, 143-154

56 Arlauckas, S.P. et al. (2017) In vivo imaging reveals a tumor-associated macrophage mediated resistance pathway in anti-PD-1 therapy. Sci Transl Med 9,

57 Lohela, M. et al. (2014) Intravital imaging reveals distinct responses of depleting dynamic tumor-associated macrophage and dendritic cell subpopulations. PNAS 111, E5086E5095

58 June, C.H. et al. (2014) Engineered T cells for cancer therapy. Cancer Immunol Immunother 63, 969-975

59 Weigelin, B. et al. (2015) Focusing and sustaining the antitumor CTL effector killer response by agonist anti-CD137 mAb. PNAS 112, 7551-7556

60 Boldajipour, B. et al. (2016) Tumor-infiltrating lymphocytes are dynamically desensitized to antigen but are maintained by homeostatic cytokine. JCI Insight 1,

61 Ruella, M. et al. (2016) Dual CD19 and CD123 targeting prevents antigen-loss relapses after CD19-directed immunotherapies. J Clin Invest 126, 3814-3826

62 Moreau, H.D. et al. (2012) Dynamic In Situ Cytometry Uncovers T Cell Receptor Signaling during Immunological Synapses and Kinapses In Vivo. Immunity 37, 351-363

63 Victora, G.D. et al. (2010) Germinal Center Dynamics Revealed by Multiphoton Microscopy with a Photoactivatable Fluorescent Reporter. Cell 143, 592-605

64 Medaglia, C. et al. (2017) Spatial reconstruction of immune niches by combining photoactivatable reporters and scRNA-seq. Science 358, 1622-1626

65 Pasqual, G. et al. (2018) Monitoring T cell-dendritic cell interactions in vivo by intercellular enzymatic labelling. Nature 553, 496-500 
66 Gautier, A. et al. (2014) How to control proteins with light in living systems. Nature Chemical Biology 10, 533-541

67 Tischer, D. and Weiner, O.D. (2014) Illuminating cell signalling with optogenetic tools. Nature Reviews Molecular Cell Biology 15, 551-558

$68 \mathrm{Xu}, \mathrm{Y}$. et al. (2014) Optogenetic control of chemokine receptor signal and T-cell migration. PNAS 111, 6371-6376

69 He, L. et al. (2015) Near-infrared photoactivatable control of $\mathrm{Ca} 2+$ signaling and optogenetic immunomodulation. eLife 4, e10024

70 Kim, K.-D. et al. (2017) Targeted calcium influx boosts cytotoxic T lymphocyte function in the tumour microenvironment. Nature Communications 8, 15365

71 Sarris, M. et al. (2016) Manipulating leukocyte interactions in vivo through optogenetic chemokine release. Blood 127, e35-e41

72 Yousefi, O.S. et al. (2019) Optogenetic control shows that kinetic proofreading regulates the activity of the T cell receptor. eLife 8, e42475

73 Tischer, D.K. and Weiner, O.D. (2019) Light-based tuning of ligand half-life supports kinetic proofreading model of T cell signaling. eLife 8, e42498

74 Thestrup, T. et al. (2014) Optimized ratiometric calcium sensors for functional in vivo imaging of neurons and T lymphocytes. Nature Methods 11, 175-182

75 Snippert, H.J. et al. (2010) Intestinal Crypt Homeostasis Results from Neutral Competition between Symmetrically Dividing Lgr5 Stem Cells. Cell 143, 134-144 
Table 1. Tumor models, anatomical sites and immune cells used in intravital imaging studies.

\begin{tabular}{|c|c|c|c|c|}
\hline $\begin{array}{c}\text { Site of } \\
\text { imaging }\end{array}$ & Tumor model & Immune cells & Window chamber & Refs. \\
\hline \multirow{15}{*}{ Skin } & \multirow{3}{*}{ EL4 or EG7 $\left(\mathrm{OVA}^{+}\right)$murine thymoma s.c. } & $\mathrm{T}$ & & {$[16,23-25]$} \\
\hline & & NK and $\mathrm{T}$ & & [27] \\
\hline & & NK & & [51] \\
\hline & B16 murine melanoma s.c or epicutaneous & $\mathrm{T}_{\mathrm{RM}}$ & & [26] \\
\hline & \multirow{2}{*}{ B16 murine melanoma s.c. } & Tregs, CTL, DC, N & & [41] \\
\hline & & CTL & & {$[53,59]$} \\
\hline & B78 murine melanoma i.d. & NK, DC & & {$[36]$} \\
\hline & 4T1 murine breast cancer s.c. & CTL & & {$[54]$} \\
\hline & MCA-OVA murine fibroscarcoma s.c. & CTL, DC & & {$[32]$} \\
\hline & LBP murine fibrosarcoma s.c. & TAM & Dorsal window & [10] \\
\hline & \multirow{2}{*}{ CT26 murine colon carcinoma s.c. } & CTL & & {$[21]$} \\
\hline & & CTL, Tregs, APC & & {$[39]$} \\
\hline & \multirow[t]{2}{*}{ MC38 murine colon cancer s.c. } & T, TAM & & {$[43,56]$} \\
\hline & & $\mathrm{T}, \mathrm{DC}$ & Dorsal skinfold & [11] \\
\hline & Human colorectal cancer $\mathrm{CEA}^{+}$s.c. & $\mathrm{T}$ & Dorsal skinfold & {$[12]$} \\
\hline \multirow{3}{*}{ Lung } & 4T1 murine breast cancer orthotopically & $\mathrm{N}$ & & {$[45]$} \\
\hline & MCA-205 murine fibrosarcoma cells i.v. & $\mathrm{T}$ & & [42] \\
\hline & B16.F10 murine melanoma i.v. & $\mathrm{N}, \mathrm{Mo}, \mathrm{DC}$ & Intercostal window & [13] \\
\hline \multirow{3}{*}{$\begin{array}{c}\text { Mammary } \\
\text { fatpads }\end{array}$} & \multirow{3}{*}{ Spontaneous breast tumors in MMTV-PyMT mice } & $\mathrm{T}, \mathrm{DC}$ & & [35] \\
\hline & & TAM & & {$[44]$} \\
\hline & & TAM, DC & & [57] \\
\hline Pancreas & 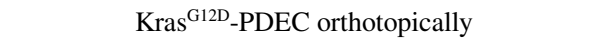 & CTL, Tregs, DC & & [40] \\
\hline \multirow{4}{*}{ Lymph nodes } & B16.F0 murine melanoma s.c. & TAM, FDC, B & & [33] \\
\hline & CT44 murine colon carcinoma f.p & CTL, Tregs, B & & [37] \\
\hline & MCA-OVA murine fibroscarcoma s.c. & CTL, Tregs, DC & & [38] \\
\hline & E $\mu$-myc murine B-cell lymphoma i.v. & CTL & & {$[55]$} \\
\hline \multirow{4}{*}{ Bone marrow } & \multirow{2}{*}{ E $\mu$-myc murine B-cell lymphoma i.v. } & CTL & & {$[20]$} \\
\hline & & CAR T & & {$[17]$} \\
\hline & Human B-cell acute leukemia xenograft i.v. & CAR T & & {$[61]$} \\
\hline & Spontaneous B-cell acute leukemia BCR-ABL ${ }^{+}$ & $\mathrm{T}$ & & [42] \\
\hline Liver & 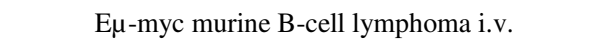 & $\mathrm{KC}$ & & {$[48,50]$} \\
\hline Kidney & EL4 murine thymoma i.v. & CTL, DC & & [32] \\
\hline Cecum & SL4 or CT26 murine colorectal cancer orthotopically & Mo & Cecum window & [14] \\
\hline Cranial & CT2A and GL261 murine glioma intracranially & TAM & Cranial window & [15] \\
\hline \multirow{3}{*}{$\begin{array}{c}\text { Human } \\
\text { cancer slices }\end{array}$} & Breast cancer & TAM & & [10] \\
\hline & Lung cancer & TAM, CTL & & {$[29,31]$} \\
\hline & Ovarian and lung cancer & CTL & & {$[30]$} \\
\hline
\end{tabular}


s.c.: subcutaneous; i.d.: intradermal; i.v.: intravenous; f.p.: footpad; T: T cells; B: B cells; CTL: cytotoxic T lymphocytes; $\mathrm{T}_{\mathrm{RM}}$ : tissue-resident memory $\mathrm{T}$ cells; Tregs: regulatory $\mathrm{T}$ lymphocytes; CAR T: chimeric antigen receptor T cells; NK: natural killer cell; APC: antigen-presenting cell; DC: dendritic cell; FDC: follicular dendritic cells; TAM: tumor-associated macrophages; Mo: monocytes; N: neutrophils; KC: Kupffer cells. 


\section{Figure legends}

Figure 1, Key Figure. Intravital imaging provides access to dynamic parameters within the tumor microenvironment.

This figure illustrates the diversity of parameters that can be collected using two-photon microscopy. Cell migration, cellular interactions, cell division or phagocytosis are readily visualized using fluorescently-labeled cells but the introduction of functional reporters has extended the list of measurable parameters including cell signaling, cell death or gene expression. For instance, nuclear translocation of nuclear factor of activated T cells (NFAT) [21] and calcium $\left(\mathrm{Ca}^{2+}\right)$ probes [17,74] have been used as readouts of TCR signaling and signal transduction respectively. Cytokine gene expression can be monitored using for example interferon gamma (IFN- $\gamma$ ) or interleukin 12 (IL-12) reporters [11]. A fluorescent probe reporting caspase-3 activity enables the detection of apoptosis in real time and in vivo $[16,17]$. Combining several of these readouts can provide unique spatiotemporal clues on immune and tumor cell activity within the tumor microenvironment.

Figure 2. Examples of genetically-encoded fluorescent reporters for the study of hosttumor interactions.

The left column depicts examples of reporters expressed by tumor cells. Tumor apoptosis has been visualized in real-time using a Förster resonance energy transfer (FRET)-based reporter for caspase-3 activity. Cyan fluorescent protein (CFP) and yellow fluorescent protein (YFP) are linked by the DEVD peptide, which is cleaved upon caspase- 3 activation, resulting in loss of FRET in apoptotic cells [16,17]. Based on genetic recombination [19] or on multicolor ex vivo labeling of tumor cells [20], multicolor barcoding strategies have been employed to investigate intratumoral spatial architecture and clonal heterogeneity. As example for genetic 
recombination, a multicolor reporter is depicted [75]. Upon Cre recombinase activation, various fluorescent proteins (nuclear green fluorescent protein (GFP), YFP, red fluorescent protein (RFP) and membrane CFP) are randomly expressed. A proliferation sensor (fluorescence ubiquitination cell cycle indicator (FUCCI)) enabled visualization of cell-cycle dynamics in real-time in individual tumor cells [18].

The right column shows some reporters expressed by immune cells. Fluorescent sensors for calcium signaling can be used to detect productive T cell contacts. An example is the Twitch2B calcium indicator in which FRET occurs upon calcium-binding to troponin $\mathrm{C}$ (TnC) $[17,74]$. Reporter mice have been developed to monitor gene activation at the single-cell level. For example, IL-12 and IFN- $\gamma$ reporters use an internal ribosome entry site (IRES) to express enhanced YFP (eYFP) following cytokine gene activation [11]. Nuclear translocation of NFAT-GFP has been used as a readout for TCR signaling [21].

Figure 3. Examples of intravital imaging applications to assess mechanisms of immunosurveillance, or the effects of immunotherapies in vivo in mice.

This figure compiles time-lapse images from different studies illustrating mechanisms of intratumoral immune activity identified by intravital imaging. Images are representative of A) Immunosuppression by regulatory $\mathrm{T}$ cells (Tregs) forming transient contacts with antigen-presenting cells (APCs) as visualized by two-photon imaging using a dorsal skinfold chamber. Scale bar, 10 $\mu \mathrm{m}$. Adapted from [39]. B) A crosstalk during anti-PD-1 mAb therapy involves IL-12-producing dendritic cells and IFN- $\gamma$-producing $\mathrm{T}$ cells as visualized by two-photon microscopy using cytokine reporter mice. Arrows highlight IL-12p40-eYFPexpressing cells. TAM, tumor-associated macrophages. Scale bar, 30 $\mu \mathrm{m}$. Adapted from [11]. C) In vivo two-photon imaging has been used to track the fate of anti-PD-1 mAb (aPD-1) revealing rapid capture by TAM. Yellow arrows indicate sites of anti-PD-1 mAb 
binding to $\mathrm{CD}^{+} \mathrm{T}$ cells at $15 \mathrm{~min}$. At $30 \mathrm{~min}$, anti-PD-1 $\mathrm{mAb}$ is internalized in macrophages. Scale bar, 30 $\mu \mathrm{m}$. Adapted from [56]. D) Multicolor tumor labeling can help visualize the extent of clonal heterogeneity in a developing lymphoma in the bone marrow. Scale bar, 50 $\mu \mathrm{m}$. Adapted from [20]. E) Visualizing tumor cell apoptosis can reveal rapid and direct killing activity of chimeric antigen receptor (CAR) T cells in the bone marrow. Red arrowheads show a CAR T cell coming into contact with a tumor cell (dotted circle)

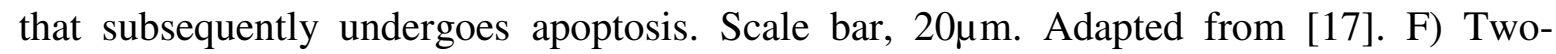
photon imaging after treatment with an anti-CD20 antibody highlights rapid and efficient B cell phagocytosis by resident macrophages in the liver. Scale bar, $25 \mu \mathrm{m}$. Adapted from [50]. G) Time-lapse images reveal tissue-resident memory $\mathrm{T}\left(\mathrm{T}_{\mathrm{RM}}\right)$ cells dynamically surveying B16 melanoma cells in the skin. Second harmonic generation (SHG) is a labelfree signal that can help visualize collagen fibers. Scale bar, $25 \mu \mathrm{m}$. Adapted from [26]. H) Cytotoxic $\mathrm{CD}^{+} \mathrm{T}$ lymphocytes and NK cells exhibit distinct behaviors during target cell killing in lymph nodes. Individual micrographs (effectors in green, targets in red) are shown for cells establishing contacts, revealing $\mathrm{CD}^{+} \mathrm{T}$ cells maintaining contacts with moving targets (superimposed tracks), whereas NK cells transiently interact with their

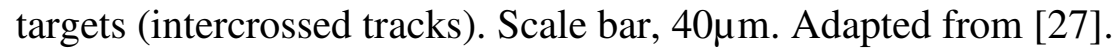

